\title{
Progression of Tau Pathology in Cholinergic Basal Forebrain Neurons in Mild Cognitive Impairment and Alzheimer's Disease
}

\author{
Laurel Vana, ${ }^{*}$ Nicholas M. Kanaan, ${ }^{\dagger}$ \\ Isabella C. Ugwu, ${ }^{*}$ Joanne Wuu, ${ }^{\ddagger}$ \\ Elliott J. Mufson, ${ }^{\S}$ and Lester I. Binder* \\ From the Department of Cell and Molecular Biology,* Feinberg \\ School of Medicine, Northwestern University, Chicago, Illinois; the \\ Department of Translational Science and Molecular Medicine, ${ }^{\dagger}$ \\ College of Human Medicine, Michigan State University, Grand \\ Rapids, Michigan; the Department of Neurology, ${ }^{\ddagger}$ University of \\ Miami, Miami, Florida; and the Department of Neurological \\ Sciences, ${ }^{\S}$ Rush University Medical Center, Chicago, Illinois
}

Tau is a microtubule-associated protein that forms neurofibrillary tangles (NFTs) in the selective vulnerable long projection neurons of the cholinergic basal forebrain (CBF) in Alzheimer's disease (AD). Although CBF neurodegeneration correlates with cognitive decline during AD progression, little is known about the temporal changes of tau accumulation in this region. We investigated tau posttranslational modifications during NFT evolution within the CBF neurons of the nucleus basalis (NB) using tissue from subjects with no cognitive impairment, mild cognitive impairment, and AD. The pS422 antibody was used as an early tau pathology marker that labels tau phosphorylated at Ser422; the TauC3 antibody was used to detect later stage tau pathology. Stereologic evaluation of NB tissue immunostained for pS422 and TauC3 revealed an increase in neurons expressing these tau epitopes during disease progression. We also investigated the occurrence of pretangle tau events within cholinergic NB neurons by dual staining for the cholinergic cell marker, p75 ${ }^{\text {NTR }}$, which displays a phenotypic down-regulation within CBF perikarya in AD. As pS422+ neurons increased in number, $\mathbf{p} 75^{\mathrm{NTR}}+$ neurons decreased, and these changes correlated with both AD neuropathology and cognitive decline. Also, NFTs developed slower in the CBF compared with previously examined cortical regions. Taken together, these results suggest that changes in cognition are associated with pretangle events within NB cholinergic neurons before frank
NFT deposition. (Am J Pathol 2011, 179:2533-2550; DOI: 10.1016/j.ajpath.2011.07.044)

Degeneration of the cholinergic basal forebrain (CBF) neurons, which provide the major cholinergic innervation to the entire cortical mantle, hippocampus, and amygdala ${ }^{1,2}$ correlates with dementia severity, disease duration, and cognitive impairment ${ }^{3,4}$ in Alzheimer's disease (AD). ${ }^{3,5-9}$ The viability of CBF neurons is dependent on the prototypic neurotrophic substance, nerve growth factor (NGF), ${ }^{10}$ which is retrogradely transported to CBF neurons through a complex interaction of its two receptors, the high-affinity NGF-specific cell survival tyrosine kinase (trkA) and the putative cell death associated lowaffinity pan neurotrophin ( $p 75^{\mathrm{NTR}}$ ) receptor. ${ }^{11,12}$ Previous studies have identified critical changes within the basocortical cholinergic system during the progression of $A D$, indicating a shift in the balance from pro-survival to apoptotic mechanisms, before frank cellular alteration, ${ }^{13,14}$ which likely over time plays a mechanistic role in the CBF degeneration seen in AD. ${ }^{5}$

In addition to altered neurotrophic factor dysfunction coincident with disease progression, CBF neurons also develop intracellular inclusions that appear as globose neurofibrillary tangles (NFTs) and neuropil threads (NTs), hallmark tau pathologies found in AD. ${ }^{15-17}$ Tau is a microtubule-associated protein involved in normal cytoskeleton function, ${ }^{18,19}$ but in $\mathrm{AD}$ tau transitions from its relatively soluble state into filamentous aggregates. ${ }^{20}$ Braak and colleagues delineated six stages (I to VI) related to the spatial temporal distribution and progression of fila-

Supported by National Institutes of Health award P01AG14449 and AG09466 (L.I.B).

Accepted for publication July 12, 2011.

CME Disclosure: None of the authors disclosed any relevant financial relationships.

Supplemental material for this article can be found at http://ajp. amjapthol.org or at doi: 10.1016/j.ajpath.2011.07.044.

Address reprint requests to Laurel Vana, Ph.D., Tarry Bldg 8-754, 300 E. Superior Street, Chicago, IL 60611. E-mail: laurelvana2010@ u.northwestern.edu. 
mentous tau inclusions during the course of $A D$, with NFTs first appearing in the transentorhinal cortex followed by the entorhinal cortex and then the hippocampus and continuing into the neocortex. ${ }^{21,22} \mathrm{CBF}$ neurons containing NFTs and associated NTs also accumulate early in the disease process as indicated by their presence at Braak stages I to III. ${ }^{15-17}$ Mesulam and co-workers reported the co-occurrence of NFTs within nucleus basalis (NB) neurons containing the cholinergic cell marker choline acetyltransferase (ChAT) in tissue harvested from persons who died with a clinical diagnosis of mild cognitive impairment (MCI), a prodromal stage of AD. ${ }^{17} \mathrm{How}$ ever, the evolution of tau events underlying the formation of NFTs within CBF neurons during the early clinical and pathological stages of $A D$ remains undetermined.

Posttranslational phosphorylation ${ }^{23-25}$ and truncation ${ }^{26}$ events are thought to contribute to tau conformational changes ${ }^{27-29}$ that accelerate the formation of filaments leading to NFTs. A linear model for NFT evolution has been proposed, which can be tracked by antibodies to tau epitopes marking early, intermediate, and late stages of NFT development in the hippocampus, temporal, and frontal cortex during the progression of AD. ${ }^{27-32}$ Phosphorylation at Ser422 was identified as an early event using the pS422 antibody, whereas truncation at the caspase cleavage site (Asp421) identified with the TauC3 antibody, occurred later during the onset of NFT formation. ${ }^{30,32,33}$ In the present study, these site-specific tau antibodies were used to gain a greater understanding of tangle evolution within the NB neurons during the onset of $A D$.

In addition to CBF neuron dysfunction, recent findings indicate that axonal and dendritic abnormalities occur during disease onset. ${ }^{34}$ For example, cholinergic axons in the entorhinal and perientorhinal cortex appear thickened and ballooned in the normal aged and early $A D$ brain. ${ }^{34}$ The aggregation of tau can also inhibit anterograde axonal transport. ${ }^{35}$ Abnormalities in axonal processes appear as tau positive NTs, which might occur before tau accumulation within the soma of the neuron. ${ }^{28,36}$ The onset of axonal/dendritic pathology within the $\mathrm{CBF}$ and its relation to cholinergic neuronal NFT development during the progression of $A D$ remains unresolved.

In the present study, we evaluated CBF tau neuronal pathology using tissue harvested from a cohort of individuals with a clinical diagnosis of no cognitive impairment $(\mathrm{NCl})$, with $\mathrm{MCl}$, or with $A D$ at the time of death. We found that the amount of the NTs containing the early tau marker, pS422, correlated with cognitive decline and disease progression. In addition, increases in the number of CBF neurons containing pS422 tau pathology were associated with a loss of p75 ${ }^{\text {NTR }}$ positive $(+)$ cholinergic neurons, which was significantly correlated with neuropathological and clinical criteria. Within CBF neurons, increased pS422 immunoreactivity correlated with both $A D$ neuropathology and cognitive scores across all three clinical groups, whereas the increase in TauC3 immunoreactivity (an early NFT marker) was not significantly associated with these variables. These data suggest that changes in cognition are associated with pretangle pathological events and NT formation before the deposition of frank NFTs within the CBF during the onset of $A D$.

\section{Materials and Methods}

\section{Subjects}

All subjects were participants in the Religious Orders Study, a longitudinal clinical-pathological study of aging and $A D$ of elderly retired Catholic clergy ${ }^{13,37-39}$ who agreed to an annual clinical evaluation beginning at 65 years of age and brain donation at time of death. Follow-up participation in the annual evaluations exceeds $95 \%$ of survivors, and the autopsy rate is greater than 90\%. The Human Investigation Committee of Rush University Medical Center approved this study. The present investigation is based on 35 individuals who, at the time of autopsy, had a clinical diagnosis of $\mathrm{NCl}(n=12), \mathrm{MCl}$ $(n=13)$, or $\mathrm{AD}(n=10 ;$ Table 1$)$. All subjects came to autopsy without coexisting clinical conditions contributing to cognitive impairment, as judged by the examining neurologist.

\section{Clinical Evaluation}

The clinical evaluation was designed to establish the presence of impaired cognition and dementia for identification of symptoms that could result in eventual $A D$. Details of the clinical evaluation have been previously reported. ${ }^{13,37-41}$ Briefly, a team of investigators led by a neurologist performed the evaluation annually. The evaluation included a medical history and interview for common problems of older persons, a complete neurological examination, and a battery of cognitive tests chosen to measure a range of cognitive abilities with emphasis on those affected by aging and AD. ${ }^{42-49} \mathrm{~A}$ board-certified neuropsychologist, blinded to age, sex, race/ethnicity, and clinical data other than occupation, education, and information about motor or sensory deficits and effort, used these results to summarize impairment in each of the five cognitive domains (orientation, attention, memory, language, and perception ${ }^{50,51}$ ), scoring them as not present, possible, or probable. After the review of all clinical data from that year and examination of the participant, a clinical diagnosis was made. The diagnosis of dementia and $A D$ followed the recommendations of the joint working group of the National Institute of Neurological and Communicative Disorders and Stroke and the Alzheimer's Disease and Related Disorders Association. ${ }^{52} \mathrm{MCl}$ was defined as those persons impaired on neuropsychological testing by the neuropsychologist but who were not found to have dementia by the examining neurologist as previously described. ${ }^{37,38}$ These criteria are compatible with those used by others in the field. ${ }^{43,46,53-56}$ A consensus conference of neurologists and neuropsychologists, who reviewed all available clinical data and assigned a summary clinical diagnosis. Cases with complicating conditions, such as stroke, Parkinson's disease, Lewy Body disease, and depression were excluded. 
Table 1. Clinical, Demographic, and Neuropathological Characteristics by Diagnosis Category

\begin{tabular}{|c|c|c|c|c|c|}
\hline & \multicolumn{3}{|c|}{ Clinical diagnosis } & \multirow[b]{2}{*}{$\begin{array}{c}\text { Total } \\
(N=35)\end{array}$} & \multirow{2}{*}{$\begin{array}{c}\text { Comparison by } \\
\text { diagnosis group } \\
(P \text { value })\end{array}$} \\
\hline & $\begin{array}{c}\mathrm{NCl} \\
(N=12)\end{array}$ & $\begin{array}{c}\mathrm{MCl} \\
(N=13)\end{array}$ & $\begin{array}{c}\mathrm{AD} \\
(N=10)\end{array}$ & & \\
\hline \multicolumn{6}{|l|}{ Age at death (years) } \\
\hline $\begin{array}{l}\text { Mean } \pm \mathrm{SD} \\
\text { (Range) }\end{array}$ & $\begin{array}{c}86.0 \pm 4.8 \\
(78-93)\end{array}$ & $\begin{array}{c}87.3 \pm 4.7 \\
(79-94)\end{array}$ & $\begin{array}{l}87.9 \pm 5.5 \\
(76-95)\end{array}$ & $\begin{array}{r}87.0 \pm 4.9 \\
(76-95)\end{array}$ & $0.6^{*}$ \\
\hline No. (\%) of males & $5(42 \%)$ & $6(46 \%)$ & $3(30 \%)$ & $14(40 \%)$ & $0.8^{+}$ \\
\hline \multicolumn{6}{|l|}{ Years of education } \\
\hline $\begin{array}{l}\text { Mean } \pm \text { SD } \\
\text { (Range) }\end{array}$ & $\begin{array}{c}18.0 \pm 3.1 \\
(10-21)\end{array}$ & $\begin{array}{c}17.9 \pm 2.4 \\
(12-20)\end{array}$ & $\begin{array}{l}18.2 \pm 3.8 \\
(14-26)\end{array}$ & $\begin{array}{r}18.0 \pm 3.0 \\
(10-26)\end{array}$ & $0.8^{*}$ \\
\hline No. (\%) with ApoE \pm 4 allele & $1(8 \%)$ & $6(46 \%)$ & $5(50 \%)$ & $12(34 \%)$ & $0.057^{\dagger}$ \\
\hline \multicolumn{6}{|l|}{ MMSE } \\
\hline $\begin{array}{l}\text { Mean } \pm S D \\
\text { (Range) }\end{array}$ & $\begin{array}{c}28.3 \pm 1.4 \\
(26-30)\end{array}$ & $\begin{array}{c}27.3 \pm 2.5 \\
(22-30)\end{array}$ & $\begin{array}{l}20.1 \pm 6.1 \\
(11-28)\end{array}$ & $\begin{array}{r}25.6 \pm 5.0 \\
(11-30)\end{array}$ & $0.0008^{\star \neq}$ \\
\hline \multicolumn{6}{|l|}{ Global Cognitive Score } \\
\hline $\begin{array}{l}\text { Mean } \pm \text { SD } \\
\text { (Range) }\end{array}$ & $\begin{array}{c}0.49 \pm 0.24 \\
(0.14-0.94)\end{array}$ & $\begin{array}{c}0.19 \pm 0.32 \\
(-0.52,0.63)\end{array}$ & $\begin{array}{c}-0.67 \pm 0.36 \\
(-1.17,-0.19)\end{array}$ & $\begin{array}{c}0.05 \pm 2.48 \\
(-1.17,0.94)\end{array}$ & $<0.0001^{* \ddagger}$ \\
\hline \multicolumn{6}{|l|}{ Postmortem interval (hours) } \\
\hline $\begin{array}{l}\text { Mean } \pm \mathrm{SD} \\
\text { (Range) }\end{array}$ & $\begin{array}{l}5.5 \pm 2.1 \\
(3.1-9.8)\end{array}$ & $\begin{array}{l}5.8 \pm 2.9 \\
(2.0-11.5)\end{array}$ & $\begin{array}{l}4.8 \pm 2.4 \\
(1.5-8.2)\end{array}$ & $\begin{array}{l}5.4 \pm 2.5 \\
(1.5-11.5)\end{array}$ & $0.7^{*}$ \\
\hline \multicolumn{6}{|l|}{ Braak scores } \\
\hline I-II & 3 & 1 & 1 & 5 & \\
\hline III-IV & 8 & 9 & 6 & 23 & $0.2^{*}$ \\
\hline $\mathrm{V}-\mathrm{VI}$ & 1 & 3 & 3 & 7 & \\
\hline \multicolumn{6}{|c|}{ NIA Reagan diagnosis (likelihood of AD) } \\
\hline No $A D$ & 0 & 0 & 0 & 0 & \\
\hline Low & 6 & 4 & 1 & 11 & $0.082^{*}$ \\
\hline Intermediate & 6 & 7 & 7 & 20 & \\
\hline High & 0 & 2 & 2 & 4 & \\
\hline \multicolumn{6}{|c|}{ CERAD diagnosis (likelihood of AD) } \\
\hline No $A D$ & 2 & 3 & 0 & 5 & \\
\hline Low & 3 & 0 & 0 & 3 & $0.057^{*}$ \\
\hline Intermediate & 6 & 7 & 6 & 19 & \\
\hline High & 1 & 3 & 4 & 8 & \\
\hline
\end{tabular}

*Kruskal-Wallis test.

†'Fisher's exact test.

†Pairwise comparisons with Bonferroni correction showed that there was no significant difference between $\mathrm{NCl}$ and $\mathrm{MCl}$, but both were significantly different from $A D$.

\section{Brain Tissue Preparation and Pathological Evaluation}

At autopsy (mean postmortem interval, 5.4 hours; range, 1.5 to 11.5 hours; Table 1), brains were removed from the calvarium and processed as described previously. ${ }^{37,38}$ After removal from the calvarium, one hemisphere of each brain was cut on a brain slice apparatus into 1-cmthick slabs, immersion fixed in $4 \%$ paraformaldehyde in $0.1 \mathrm{~mol} / \mathrm{L}$ phosphate buffer, $\mathrm{pH} 7.2$, for 48 hours at $4^{\circ} \mathrm{C}$, and cryoprotected in $10 \%$ glycerol plus $2 \%$ dimethyl sulfoxide (DMSO) in $0.1 \mathrm{~mol} / \mathrm{L}$ phosphate buffer and at $4^{\circ} \mathrm{C}$ for 2 to 7 days, followed by immersion in a solution of $20 \%$ glycerol plus 2\% DMSO. Brain slabs containing the CBF were cut into 18 series $(720-\mu \mathrm{m}$ interval) of adjacent $40-\mu \mathrm{m}$-thick sections on a freezing stage, sliding microtome and stored in cryoprotectant solution until processed. ${ }^{37,38}$ Tissue from the opposite hemisphere was paraffin embedded, cut at $8 \mu \mathrm{m}$, and stained with hematoxylin and eosin, modified Bielschowsky, thioflavin-S, and a ubiquitin antibody. ${ }^{57} \mathrm{~A}$ complete neuropathological evaluation was performed in each case; special attention was given to dementia-related pathological lesions, such as strokes and cortical Lewy bodies, which may contribute to dementia.
A pathological diagnosis was made for all cases. Designations of "normal" (with respect to AD or other dementing processes), "possible" or "probable AD," and "definite $A D$ " were based on semiquantitative estimation of neuritic plaque density, an age-adjusted plaque score, and presence or absence of dementia as established by the Consortium to Establish a Registry for Alzheimer's Disease (CERAD). ${ }^{58}$ Braak scores based on the staging of neurofibrillary tangle pathology were also assigned to each case. ${ }^{22}$

\section{Antibody Characterization}

The rabbit polyclonal anti-Tau pS422 antibody was raised against a chemically synthesized phosphopeptide that is phosphorylated at serine 422 and affinity purified (manufacturer's technical information; Invitrogen, Carlsbad, CA). The specificity of the antibody was determined by Western blotting using GSK-3 (+/-) treatment to determine the phosphospecificity of the antibody (Invitrogen, Carlsbad, CA). Other studies have also determined the specificity of pS422 through Western blotting procedures. ${ }^{59-62}$ In addition, immunostaining with pS422 has identified this modification within NFTs and NTs. ${ }^{32,33,63}$ In 
this study, we used pS422 to identify phosphorylation at serine 422 within the CBF neurons.

The mouse monoclonal TauC3 antibody (Binder Lab) was generated against a peptide corresponding to the truncation of the C-terminus of tau at Asp421. ${ }^{26}$ The specific peptide CSSTGSIDMVD, which corresponds to residues 412 to 421 of tau with a Cys added to the $\mathrm{N}$-terminus for ready conjugation to maleimide-activated $\mathrm{KLH}$, was used to create the antibody which was then affinity purified as described previously. ${ }^{26}$ The specificity of TauC3 was determined by Western Blotting procedures. ${ }^{26,30}$ Immuhistochemistry and immunocytochemistry also demonstrated the specificity of TauC3 labeling NFTs, NTs and NPs in AD tissue. ${ }^{26,30}$ This antibody detects neurons in which tau has just begun to coalesce into NFTs. ${ }^{30}$ In this study, TauC3 was used to identify forming NFTs in CBF neurons.

The other two antibodies used in this study were both neurotrophin receptor ( $\left.p 75^{\mathrm{NTR}}\right)$ antibodies used to detect cholinergic neurons within the CBF. A mouse monoclonal p75 ${ }^{\text {NTR }}$ antibody was created by using the nerve growth factor receptor, p $75^{\mathrm{NTR}}$, from A875 melanoma cells as the immunogen and affinity purified as described by the manufacturer (Thermo Scientific, Waltman, MA). This antibody is not suitable for Western Blotting and was characterized by immunocytochemistry and flow cytometry (Thermo Scientific, Waltman, MA). Previous work has shown the specificity of $p 75^{\mathrm{NTR}}$ for cholinergic neurons within the nucleus basalis. ${ }^{9,64,65}$ The second $p 75^{\mathrm{NTR}}$ antibody was a rabbit monoclonal antibody produced through immunization with a synthetic peptide from human nerve growth factor receptor, p75 ${ }^{\mathrm{NTR}}$, and affinity purified per the manufacturer's protocol (Epitomics, Burlingame, CA). Western blot analysis confirmed that p $75^{\text {NTR }}$ identified a single band near $75 \mathrm{kDa}$, which corresponds to the correct molecular weight of the nerve growth factor receptor (Epitomics, Burlingame, CA). Immunohistochemical techniques were also used to determine the specificity of this rabbit monoclonal for p $75^{\mathrm{NTR}}$ (Epitomics, Burlingame, CA).

\section{Immunohistochemistry}

Two separate double-label immunohistochemical procedures were applied to tissue sections containing the CBF extending from the level of the crossing of the anterior commissure to the emergence of this fiber bundle from the temporal pole. The anterior/anteriomedial (Ch4am), anterolateral (Ch4al) and intermediate (Ch4i) cholinergic subfields of the cholinergic $\mathrm{NB}^{66}$ were evaluated. Two double-label immunohistochemistry stains were performed on separate complete series of sections processed simultaneously. The first series of tissue was double-stained with a rabbit polyclonal antibody, pS422 (1: 20,000; Invitrogen, Carlsbad, CA), which identifies tau phosphorylated at serine $422^{32,33}$ and TauC3 $(1: 10,000)$, a mouse monoclonal antibody that identifies tau truncated between aspartic acid 421 and serine $4222^{26,30}$ The second series was double-stained with $\mathrm{p} 75^{\mathrm{NTR}}$, a mouse monoclonal antibody raised against human p75 ${ }^{\text {NTR }}$ (1:60,000; Thermo Scientific, Waltman, MA) a well-established marker for human CBF neurons 9,64,65 $^{9}$ and the pS422 antibody $(1: 20,000)$. The following general immunohistohemical protocol was used for each doubleimmunostain procedure. Tissues were rinsed $6 \times 10 \mathrm{~min}$ utes with $0.1 \mathrm{~mol} / \mathrm{L}$ phosphate-buffered saline (PBS; $\mathrm{pH}$ 7.4) containing $0.04 \%$ Triton $X-100$ (TxPBS) before each step of the staining process. To quench endogenous peroxidase activity the tissue was incubated in $3 \% \mathrm{H}_{2} \mathrm{O}_{2}$ for 1 hour at room temperature. Nonspecific binding was inhibited by incubating for 1 hour in a blocking buffer containing 10\% goat serum (GS)/2\% bovine serum albumin (BSA)/TxPBS. The tissue was then incubated overnight at $4^{\circ} \mathrm{C}$ in primary antibody in dilution buffer $(2 \%$ GS-TxPBS). The following day, the tissue was further incubated in primary antibody for 1 hour at room temperature. The tissue was next incubated in the appropriate biotinylated secondary antibody (Vector Laboratories, Burlingame, CA) at a concentration of 1:500 in dilution buffer for 2 hours at room temperature before incubation for 1 hour at room temperature in avidin-biotin complex (ABC) solution (Vector Laboratories, Burlingame, CA) made according to the manufacturer's instructions. Tissue was then developed in $0.05 \% 3^{\prime}, 3^{\prime}$-diaminobenzidine (DAB) and $0.005 \% \mathrm{H}_{2} \mathrm{O}_{2}$ resulting in a brown reaction product.

After the development of the first antigen, tissue was soaked in an avidin/biotin blocking kit (Vector Laboratories, Burlingame, CA) following the recommendations of the manufacturer. Any remaining peroxidase activity derived from the first reaction was quenched with $3 \% \mathrm{H}_{2} \mathrm{O}_{2}$ for 30 minutes at room temperature. Blocking buffer was reapplied for 1 hour at room temperature, and the tissue was incubated overnight at $4^{\circ} \mathrm{C}$ in the second primary antibody in dilution buffer. The next day, the tissue continued to incubate in primary antibody for 1 hour at room temperature before incubation with the appropriate biotinylated secondary antibody (1:500 in dilution buffer; Vector Laboratories, Burlingame, CA) for 2 hours at room temperature. Tissues were then incubated in $A B C$ solution as described above. All tissue was developed with the Vector SG Substrate Kit (blue reaction product; Vector Laboratories, Burlingame, CA) according to the manufacturer's protocol. After development, the tissue was mounted on microscope slides, air dried, dehydrated in a series of graded concentrations of ethanols $(70 \%, 90 \%$, $95 \%$, and $100 \%$ ), cleared in xylenes, and coverslipped using Permaslip (Alban Scientific, Inc., St. Louis, MO).

Immunohistochemical controls were completed to rule out any cross-reactivity or nonspecific staining. Omission of both primary antibodies resulted in no detectable immunostaining. For the double immunostains the following two sets of controls were performed: 1) omission of the first primary antibody, or 2) omission of the second primary antibody. These controls ensured that the blocking/ quenching steps were effective and that there was no cross-reactivity of the primary or secondary antibodies, meaning that each stain was detecting only the specific epitope of the primary antibody. All controls produced the expected results (data not shown). 


\section{Immunofluorescence}

Additional basal forebrain sections from three $\mathrm{NCl}$, three $\mathrm{MCl}$, and three AD cases, selected from the above cases were processed for immunofluorescence to determine the relationship between tau pathology (presence of pS422 or TauC3) and the cholinergic phenotypic marker, p75 NTR. Two different double immunostains were used for these qualitative analyses. Tissues were rinsed with TxPBS before each step of the staining process and all steps were performed at room temperature unless otherwise indicated. For the first double stain, tissue was incubated in blocking buffer (as above) for 1 hour to inhibit nonspecific binding and then tissue sections were incubated overnight at $4^{\circ} \mathrm{C}$ in a primary antibody solution containing monoclonal mouse p75 NTR $(1: 1000)$ in dilution buffer. The next day, the tissue was incubated for 2 hours with the goat anti-mouse Alexa-Fluor 488 secondary antibody (1:500 in dilution buffer, Invitrogen, Carlsbad, CA) and then re-blocked for 1 hour. The tissue sections were then incubated in the rabbit anti-pS422 antibody (1: $10,000)$ at $4^{\circ} \mathrm{C}$ overnight in dilution buffer. The next day, the tissue was incubated in goat anti-rabbit Alexa-Fluor 546 secondary antibody (1:500 in dilution buffer, Invitrogen, Carlsbad, CA), and then mounted on microscope slides and air-dried. To block autofluorescence the slides were dehydrated in $70 \%$ ethanol for 3 minutes, incubated in $0.005 \%$ Sudan black for 3 minutes, rinsed and coverslipped using Vectashield mounting medium (Vector Laboratories, Burlingame, CA).

For the second double immunofluorescent reaction, the same cases were used with the protocol described above with the exception that the first primary antibody was rabbit anti-p75 NTR (1:1000; Epitomics, Burlingame, $\mathrm{CA}$ ) and the first secondary antibody was goat anti-rabbit Alexa-Fluor 488 (1:500; Invitrogen, Carlsbad, CA), whereas the second primary antibody was TauC3 (1: 2500) and the second secondary antibody was goat antimouse Alexa-Fluor 546 (1:500; Invitrogen, Carlsbad, CA).

The immunofluorescent controls were completed using the protocol described above. Omission of both primary antibodies resulted in no detectable immunostaining. For the double immunostains, the following two sets of controls were performed: 1) omission of the first primary antibody, or 2) omission of the second primary antibody. All controls produced the expected results (data not shown). The immunofluorescent stains were visualized

Table 2. Coefficients of Error for Quantification of Each Marker

\begin{tabular}{ccc}
\hline Antibodies & Range & Average \pm SEM \\
\hline p75 $^{\text {NTR }}$ and pS422 & & \\
Stereological Count & & \\
p75 $75^{N T R}$ & $0.04-0.09$ & $0.06 \pm 0.0003$ \\
p75 & \\
pS422+ & $0.05-0.29$ & $0.10 \pm 0.0011$ \\
pS422 and TauC3 & $0.04-0.30$ & $0.08 \pm 0.0012$ \\
Stereological Count & & \\
pS422+ & $0.04-0.20$ & $0.06 \pm 0.0007$ \\
pS422+/TauC3+ & $0.04-0.38$ & $0.14 \pm 0.0025$ \\
TauC3+ & $0.07-0.71$ & $0.35 \pm 0.0085$ \\
pS422+ NTs & $0.03-0.16$ & $0.06 \pm 0.0006$ \\
\hline
\end{tabular}
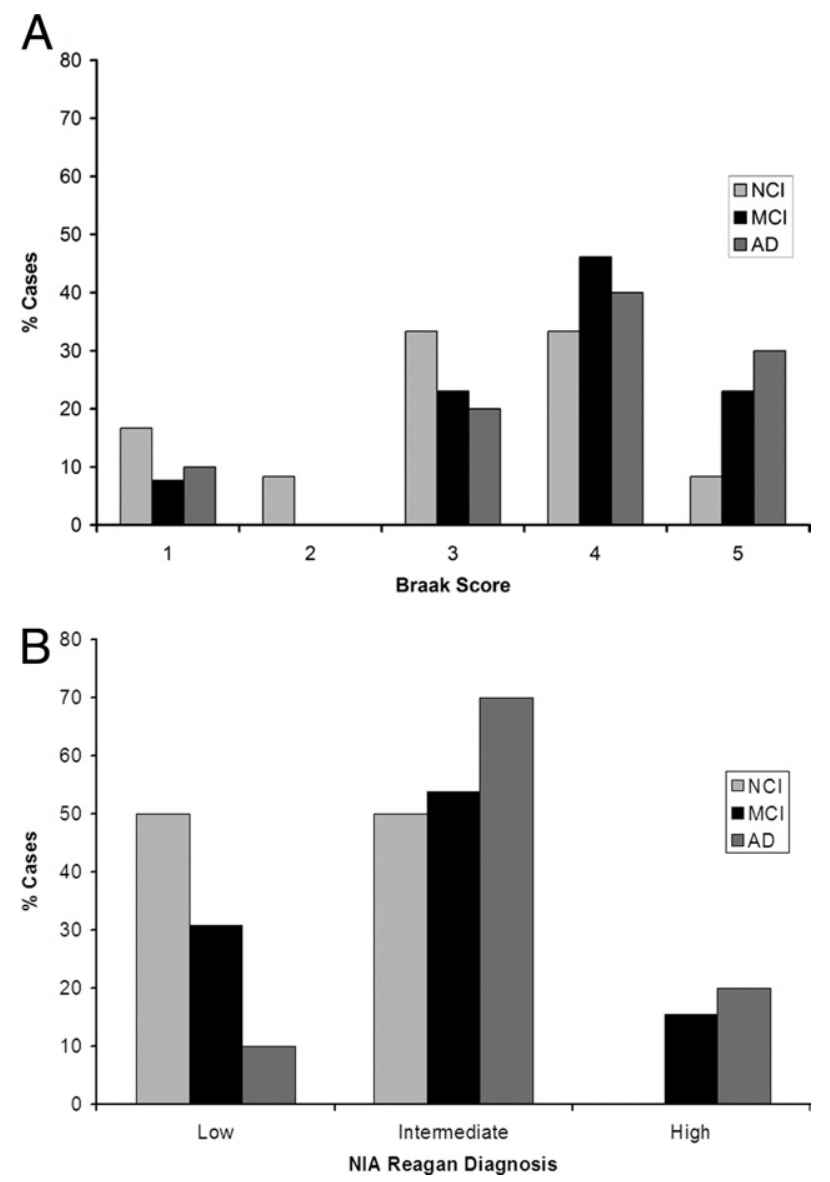

Figure 1. Difference between clinical diagnosis and neuropathological score. Histograms demonstrating the percentage of cases in each clinical group (NCI (light gray), MCI (black), and AD (dark gray), versus Braak score (A) and NIA Reagan diagnosis (B). These histograms indicate that there are several NCI and MCI cases with higher than expected Braak scores and NIA Reagan diagnoses.

using a Zeiss LSM 510 Meta laser scanning confocal microscope resident in the Northwestern University Cell Imaging Facility.

\section{Stereological Quantification of Neurons and NT Length}

Quantitative estimates of the total number of the pS422, pS422/TauC3, TauC3, p75 NTR , and p75 NTR/pS422 immunoreactive $(+)$ neurons within the NB subregions of the CBF were performed using the optical fractionator cell counting procedure. ${ }^{13,14,67-69}$ Anatomically, the region of interest included the CBF neurons extending from the crossing of the anterior commissure to its emergence at the level of the temporal pole of one hemisphere of the brain. The use of the optical fractionator method allows for the stereologic analysis of a well-defined portion of a structure independent of its size, shape, orientation, or tissue shrinkage. ${ }^{67,70,71}$ Briefly, the stereology system consisted of a Nikon Eclipse 80i microscope (Nikon Instruments, Melville, NY) hard-coupled to a MAC5000 computer-controlled $x-y-z$ motorized stage (Ludl Electronic Products, Hawthorne, NY), a Microfire A/R video 
system (Optronics, Goleta, CA) and a computer equipped with Stereolnvestigator v9.0 software (MBF Bioscience, Williston, VT). Neuronal cell counts were performed on a 1:18 series of sections that yielded approximately 12 to 15 serial sections per case. The CBF region was outlined under low magnification using a $\times 2$ objective and approximately 200 to 400 immunoreactive neurons were counted for each case at $\times 60$ magnification with a counting frame size of $10 \mathrm{~mm}^{2}$. For each cell type the percentage of the area counted was adjusted to achieve the most accurate estimate possible, but the method used for each case was uniform throughout all sections. In some cases (eg, $\mathrm{NCl}$ subjects), the amount of pS422+, TauC3+, pS422+/TauC3+, and/or p $75^{\mathrm{NTR}}+/$ pS422+ cells required analysis of $75 \%$ to $100 \%$ of the area. For the $\mathrm{p} 75^{\mathrm{NTR}}+$ neurons, $5 \%$ of the CBF was counted for all cases. The proportion of the total area analyzed for pS422+ and $\mathrm{p} 75^{\mathrm{NTR}}+/ \mathrm{pS} 422+$ neurons varied from $10 \%$ to $50 \%$. The TauC3+/pS422+ and TauC3+ neurons were fairly sparse and therefore were counted at $50 \%, 75 \%$, or $100 \%$, with only a few cases quantified at $30 \%$. The average section thickness was approximately $12 \mu \mathrm{m}$ and a guard zone consisting of 1 to $2 \mu \mathrm{m}$ was applied at both the top and bottom of each section. Coefficients of error (CE) were calculated using the Gundersen method to estimate the accuracy of the optical fractionator's results. ${ }^{67,72,73}$ The range of CE values and average CE value for each cell type can be found in Table 2. The stereologist performing the quantitative analysis was blinded to age, sex, clinical and pathological classification and cause of death for each subject analyzed.

The spaceball probe (Stereolnvestigator v.9.0, MBF Bioscience, Williston, VT) was used to quantify immuno-
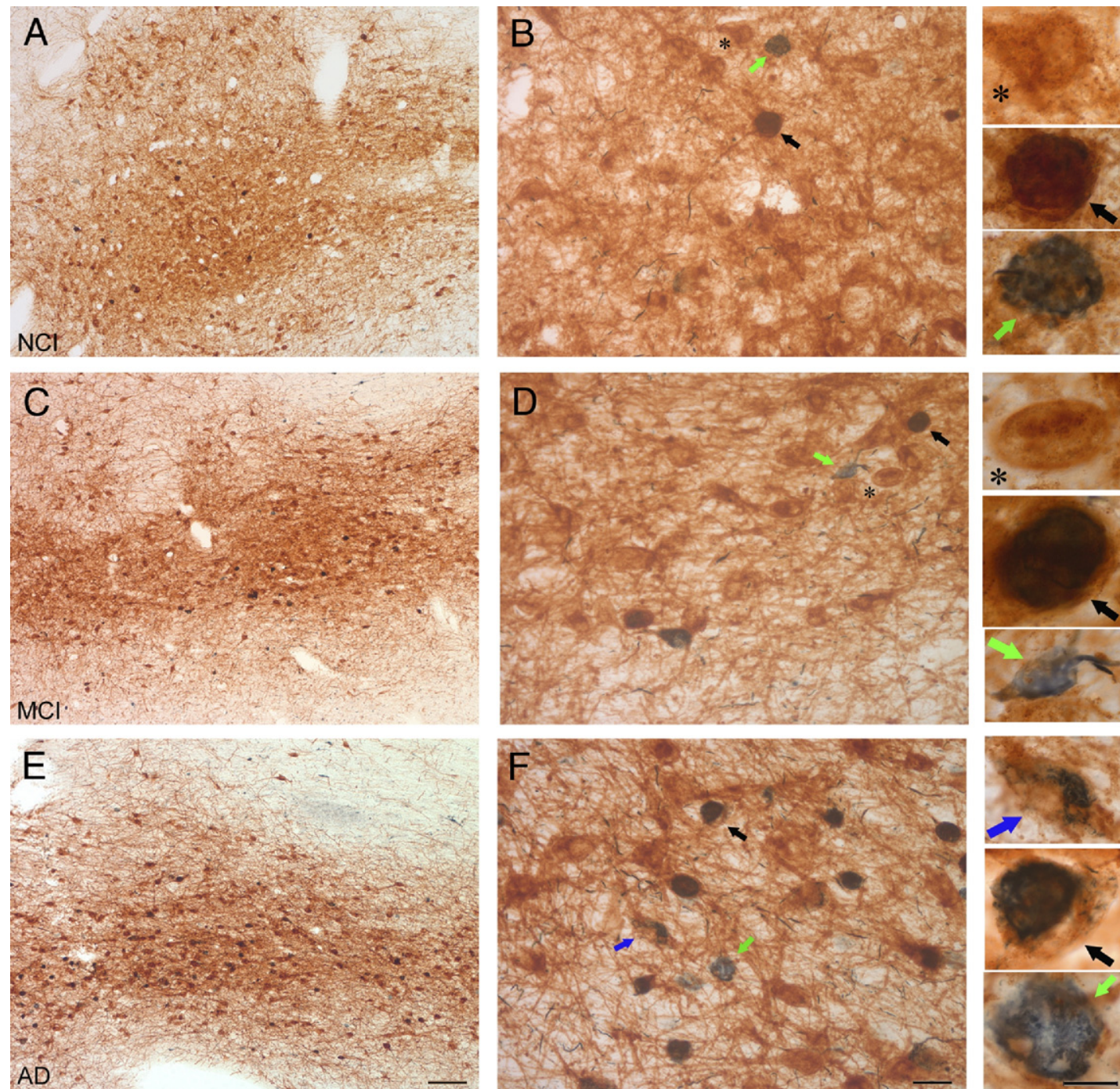

Figure 2. $\mathrm{p} 75^{\mathrm{NTR}} / \mathrm{pS} 422$ Immunolabeled neurons. Sections containing the NB subfield of the CBF dual immunostained for p75 ${ }^{\mathrm{NTR}}+($ brown) and pS422 + (blue) show a decrease in the number of p $75^{\mathrm{NTR}}+$ neurons with an increase of pS422+ neurons as disease progression continues from NCI (A and $\left.\mathbf{B}\right)$, to $\mathrm{MCI}(\mathbf{C}$ and $\mathbf{D})$ and $\mathrm{AD}$ $(\mathbf{E}$ and $\mathbf{F})$. In NCI (B), most NB neurons were single-labeled for $\mathrm{p} 75^{\mathrm{NTR}}+\left(\right.$ asterisk), few neurons were double-labeled for $\mathrm{p} 75^{\mathrm{NTR}}+/ \mathrm{pS} 422+(\mathbf{b l a c k}$ arrow), whereas only an occasional neuron was single-labeled for the early tau pathological marker, pS422+ (green arrow). In the MCI (D) and AD (F) cases, there was a decrease in the $\mathrm{p} 75^{\mathrm{NTR}}+$ neurons (asterisk) and an increase in both $\mathrm{p} 75^{\mathrm{NTR}}+/ \mathrm{pS} 422+\left(\right.$ black arrow) and pS422 + (green arrow) neurons. In some p $75^{\mathrm{NTR}}+/ \mathrm{pS} 422+$ neurons, it can be seen that the pS422 immunoreactivity begins in the center of the neuron (blue arrow). Images in $\mathbf{A}, \mathbf{C}$, and $\mathbf{E}$ were taken at magnification $\times 4$. Scale bar $=250$ $\mu \mathrm{m}$. Images in $\mathbf{B}, \mathbf{D}$, and $\mathbf{F}$ were taken at magnification $\times 20$. Scale bar is $50 \mu \mathrm{m}$. The panels to the right were taken at magnification $\times 60$. Scale bar is $25 \mu \mathrm{m}$. 
Table 3. Summary of Quantification of $\mathrm{p} 75^{\mathrm{NTR}}+, \mathrm{p} 75^{\mathrm{NTR}}+/ \mathrm{pS} 422+$, and $\mathrm{pS} 422+$ Neurons

\begin{tabular}{|c|c|c|c|c|}
\hline & \multicolumn{3}{|c|}{ Clinical diagnosis } & \multirow[b]{2}{*}{$P$ value ${ }^{\star}$} \\
\hline & $\begin{array}{c}\mathrm{NCl} \\
(N=12)\end{array}$ & $\begin{array}{c}\mathrm{MCl} \\
(N=13)\end{array}$ & $\begin{array}{c}\mathrm{AD} \\
(N=10)\end{array}$ & \\
\hline \multicolumn{5}{|l|}{$\mathrm{p} 75^{\mathrm{NTR}}+\left(\times 10^{3}\right)$} \\
\hline $\begin{array}{l}\text { Mean } \pm \text { SD } \\
\text { (Range) } \\
\text { p75 }\end{array}$ & $\begin{array}{r}212.2 \pm 51.4 \\
(123.4-297.9)\end{array}$ & $\begin{array}{l}170.5 \pm 62.1 \\
(54.5-277.0)\end{array}$ & $\begin{array}{c}169.3 \pm 42.4 \\
(115.8-252.0)\end{array}$ & 0.1 \\
\hline $\begin{array}{l}\text { Mean } \pm \mathrm{SD} \\
\text { (Range) }\end{array}$ & $\begin{array}{r}5.0 \pm 3.1 \\
(0.8-11.6)\end{array}$ & $\begin{array}{r}8.9 \pm 7.5 \\
(0.3-22.6)\end{array}$ & $\begin{array}{c}11.8 \pm 5.2 \\
(4.3 \pm 22.7)\end{array}$ & $0.024^{\dagger}$ \\
\hline \multicolumn{5}{|l|}{$\mathrm{pS} 422+\left(\times 10^{3}\right)$} \\
\hline $\begin{array}{l}\text { Mean } \pm S D \\
\text { (Range) }\end{array}$ & $\begin{array}{l}9.8 \pm 89.0 \\
(01.0-27.2)\end{array}$ & $\begin{array}{l}13.0 \pm 10.8 \\
(0.3-33.8)\end{array}$ & $\begin{array}{r}18.0 \pm 8.9 \\
(3.8-30.8)\end{array}$ & 0.1 \\
\hline
\end{tabular}

*Kruskal-Wallis test.

tPost hoc comparisons with Bonferroni correction showed that $\mathrm{AD}$ was significant higher than $\mathrm{NCl}$, but $\mathrm{MCl}$ was not significantly different from $\mathrm{AD}$ or $\mathrm{NCl}$.

reactive NT length in the sections described above. ${ }^{74}$ The surface area of the spaceball was kept constant at $402.124 \mu \mathrm{m}$. The total area counted was dependent on the amount of pS422+ NTs and ranged from $0.42 \%$ to $0.04 \%$ of the area outlined, optimized to count of 200 to 400 pS422+ NTs per case. CE values were calculated to determine the accuracy of the counts (Table 2).

\section{Statistical Analysis}

Demographic, clinical, and neuropathological characteristics were compared across clinical diagnostic groups by Kruskal-Wallis test or Fisher's exact test, with Bonferroni correction for post hoc comparison. Neuron counts were compared across clinical diagnostic groups by Kruskal-Wallis test, and assessed for association with demographic, clinical, and neuropathological variables by Spearman rank correlation (for numerical or ordinal variables such as cognitive scores or Braak scores) or Wilcoxon rank-sum test (for binary variables such as sex). Multiple regression, with adjustment for potential confounders (eg, age), was also used. Data were transformed by natural logarithm as needed. The level of statistical significant was set at 0.05 (two-sided).

\section{Results}

\section{Clinical and Pathological Characteristics}

This study included 35 cases in the following clinical diagnostic groups: $12 \mathrm{NCl}, 13 \mathrm{MCl}$, and $10 \mathrm{AD}$. The three groups were well matched in age, sex, education, and postmortem interval (Table 1). Subjects with AD had significantly lower Mini-Mental State Examination (MMSE) scores and global cognitive scores (GCS), a composite z-score based on 19 antemortem cognitive tests that reduces random variability and minimizes floor and ceiling effects, when compared with $\mathrm{MCl}$ and $\mathrm{NCl}$ cases (Table 1). Comparison of clinical and pathological diagnosis revealed that, in several cases, the Braak stage and/or National Institute on Aging (NIA) Reagan diagnosis was discordant with the clinical diagnoses (Table 1 ,
Figure 1). For instance, $1 \mathrm{NCl}$ case was a Braak stage $\mathrm{V}$ and 4 were Braak stage IV. In addition, $50 \%$ of all $\mathrm{NCI}$ cases had an intermediate likelihood of $A D$ according to NIA Reagan diagnosis. Similar findings have been reported in other clinical cohorts ${ }^{75,76}$ suggesting that either these individuals were able to tolerate medial temporal lobe NFT formation without cognitive impairment or they are preclinical $A D$ cases.

\section{Morphology and Quantitation of $p 75^{N T R}+$, $p 75^{N T R}+/ p S 422+$, and pS422 + Neurons}

Sections immunostained for $p 75^{N T R}$ revealed a continuum of positive neurons extending from the anterior medial (Ch4am), to the anterolateral (Ch4al) to the intermediate (Ch4i) subfields of the CBF as previously described.9,14 There were also interstitial $\mathrm{p} 75^{\mathrm{NTR}}+$ neurons scattered within the internal capsule, medullary laminae of the globus pallidus, ansa peduncularis, and ansa lenticularis. Sections containing the posterior (Ch4p) subfield of the nucleus basalis were not available for examination because of the method used by the Rush brain bank to harvest samples. The $\mathrm{p} 75^{\mathrm{NTR}}+$ staining exhibited a brown reaction product that filled the neuronal cytoplasm and processes (Figure 2, black asterisk). The pS422+ neurons displayed a dark blue reaction product that seemed initially to appear in discrete cytoplasmic areas in the double-labeled neurons (Figure 2F, blue arrow) progressing to fill the entire cell body, and finally extending out into the dendrites in $\mathrm{MCl}$ and $\mathrm{AD}$ (Figure $2 \mathrm{D}$ and $F$, black arrow). Single-label pS422+ neurons were often shrunken and contained globose tangle inclusions in $\mathrm{MCl}$ and $A D$ (Figure $2 D$ and $F$, green arrow), whereas only an occasional globose tangle was also found in $\mathrm{NCl}$ cases (Figure 2B, green arrow).

Quantification of the number of $\mathrm{p} 75^{\mathrm{NTR}}+, \mathrm{p} 75^{\mathrm{NTR}}+1$ pS422+, and pS422+ neurons was performed in all 35 cases across the three clinical groups (Table 3 ). The number of pS422+ neurons increased (Figure $3 \mathrm{~A}$ ) and the number of $\mathrm{p} 75^{\mathrm{NTR}}+$ neurons decreased (Figure $3 \mathrm{C}$ ) in $\mathrm{MCl}$ and $\mathrm{AD}$, although the group comparison did not reach statistical significance. There was, however, a significant increase in $\mathrm{p} 75^{\mathrm{NTR}}+/ \mathrm{pS} 422+$ neurons across 

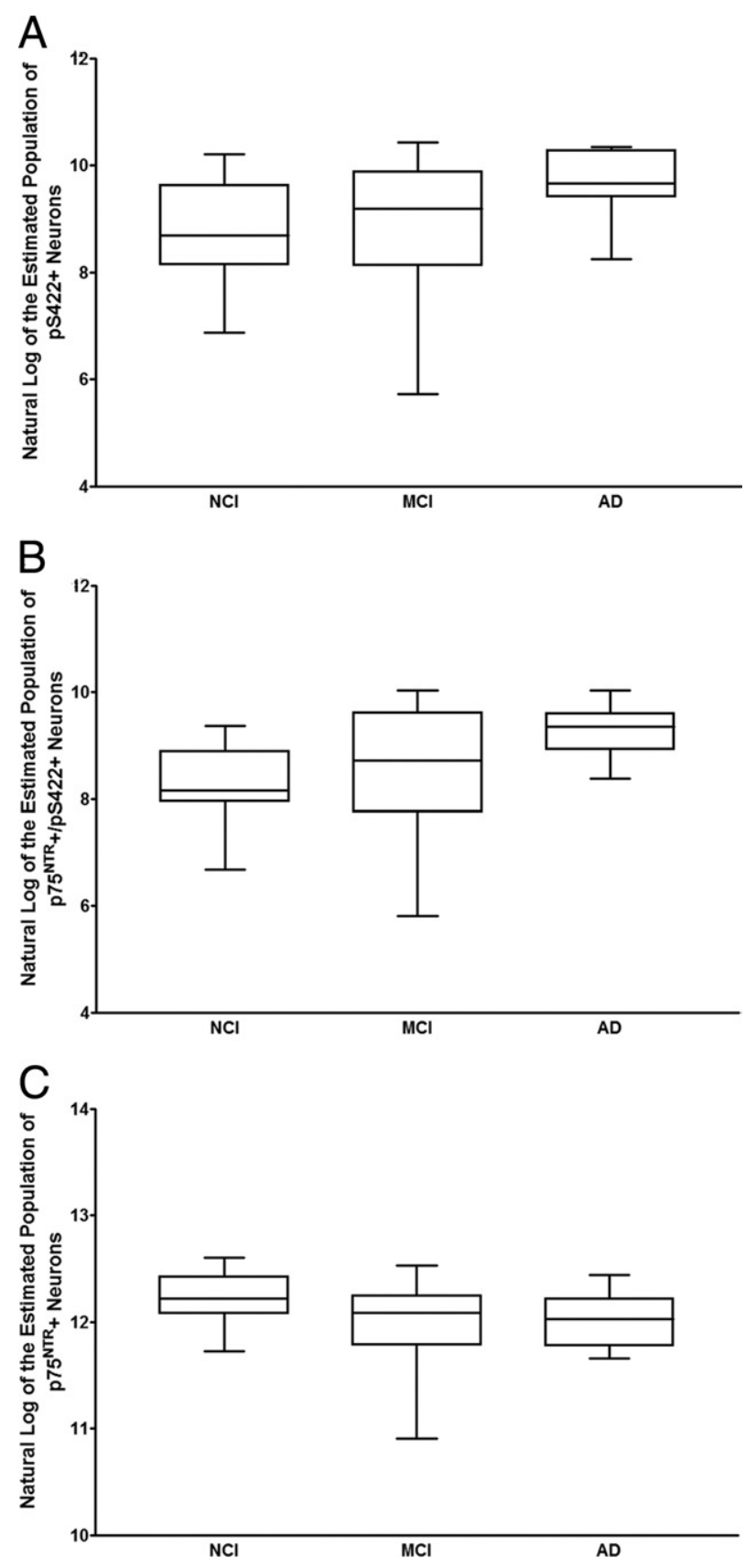

Figure 3. Quantification of the $\mathrm{p} 75^{\mathrm{NTR}}$ and $\mathrm{pS} 422$ double-stain. Box plots showing an increase in the number of pS422+ (A) and p75 $5^{\mathrm{NTR}}+/ \mathrm{pS} 422+(\mathbf{B})$ neurons from NCI to MCI and AD. C: $\mathrm{p} 75^{\mathrm{NTR}}+$ Neurons decreased from NCI to $\mathrm{MCI}$ and $\mathrm{AD}$.

$\mathrm{NCl}, \mathrm{MCl}$ and $\mathrm{AD}(P=0.024)$ (Figure 3B and Table 3). Because of case-to-case variability in the total number of p75 NTR neurons within the NB, we performed a secondary analysis by converting the number of each cell type to a percentage of the total cell count for each case. This transformed data indicated a decrease in $\mathrm{p} 75^{\mathrm{NTR}}+$ neurons relative to the increase in $p 75^{\mathrm{NTR}}+/ \mathrm{pS} 422+$ and pS422+ neurons in $\mathrm{MCl}$ and AD (see Supplemental Table S1 at http://ajp.amjpathol.org). The three-group comparison of the proportion of $\mathrm{p} 75^{\mathrm{NTR}}+$ neurons and the proportion of $\mathrm{p} 75^{\mathrm{NTR}}+/ \mathrm{pS} 422+$ neurons both reached statistical significance $(P=0.041$ and 0.028 , respectively), largely because of the difference (decrease of $8.4 \%$ for $\mathrm{p} 75^{\mathrm{NTR}}+$ and increase of $3.7 \%$ for $\mathrm{p} 75^{\mathrm{NTR}}+1$ pS422+) between $\mathrm{NCl}$ and AD (see Supplemental Table $\mathrm{S} 1$ at http://ajp.amjpathol.org). This conversion from estimated number to percentage of total neuron count indicated that a loss of p75 ${ }^{\text {NTR }}+$ neurons occurred as pS422 labeling increased in both single and double-labeled NB neurons.

\section{Neuropathological and Clinical Correlates}

We first examined the relationship between each population of labeled neurons and neuropathological criteria (eg, Braak score, NIA Reagan diagnosis, and CERAD; Table 4). A consistent, significant positive correlation was found between Braak stage and number of pS422+ (Spearman rank correlation, $r=0.80, P<0.0001$; Figure $4 \mathrm{~A})$ and $\mathrm{p} 75^{\mathrm{NTR}}+/ \mathrm{pS} 422+$ neurons $(r=0.72, P<$ 0.0001 ; Figure 4C). In addition, the increase in number of pS422+ and p75 ${ }^{\mathrm{NTR}}+/ \mathrm{pS} 422+$ neurons was significant when compared with age and select neuropathological criteria, including NIA Regan diagnosis and CERAD (Table 4). In contrast, a significant negative correlation was found between p75 NTR + neuron number and Braak stage (rho $=-0.35, P=0.034$; Figure 4E), NIA Reagan $(r=-0.57, P=0.0003)$, and CERAD $(r=-0.42, P=$ $0.013)$ diagnosis (Table 4).

Next, we examined the relationship between each of these three neuronal populations and tests of cognitive function. In this regard, both the number of double-labeled $\mathrm{p} 75^{\mathrm{NTR}}+/ \mathrm{pS} 422+(r=-0.51, P=0.0016)$ and single-labeled pS422+ $(r=-0.50, P=0.0023)$ neurons significantly correlated with GCS (Figure 4, B and D, and Table 4). Similarly, the increase in both p75 ${ }^{\mathrm{NTR}}+/ \mathrm{pS} 422+$ $(r=-0.35, P=0.040)$ and $p S 422+(r=-0.42, P=$ 0.012) neurons significantly correlated with MMSE scores (Table 4). The estimated number of p75 NTR + neurons, on the other hand, did not correlate with either cognitive measure. This suggests the appearance of the pS422 epitope in the NB is an appropriate marker of the cognitive impairment that occurs during disease progression.

\section{Morphology and Quantitation of pS422+, pS422+/TauC3+, and TauC3+ Neurons}

We further evaluated the progression of tau pathology within the CBF by double-staining for the pretangle pS422 epitope and TauC3, which is an epitope that occurs as NFTs coalesce within neurons. ${ }^{32}$ The pS422 and TauC3 double-stain did not permit the use of a cholinergic marker because of cross reactivity. Thus, CBF neurons were identified based on their anatomical location in relation to the crossing of the anterior commissure, anteriorially and its emergence from the temporal pole as well as cellular morphological characteristics (eg, perikaryal shape and size). The pS422 reaction product appeared brown, filling the cytoplasm as well as some neuronal processes (Figure 5). In NCl, single-label pS422+ neu- 
Table 4. Clinical and Neuropathological Correlations with Number of p $75^{\mathrm{NTR}}+, \mathrm{p} 75^{\mathrm{NTR}}+/ \mathrm{pS} 422+$, and pS422+ Neurons

\begin{tabular}{|c|c|c|c|}
\hline & $\mathrm{p} 75^{\mathrm{NTR}}+$ & $\mathrm{p} 75^{\mathrm{NTR}}+/ \mathrm{pS} 422+$ & pS422+ \\
\hline Age at death & NS & $\begin{array}{l}r=0.39 \\
P=0.021\end{array}$ & $\begin{array}{l}r=0.43 \\
P=0.010\end{array}$ \\
\hline MMSE & NS & $\begin{aligned} r & =-0.35 \\
P & =0.040\end{aligned}$ & $\begin{aligned} r & =-0.42 \\
P & =0.012\end{aligned}$ \\
\hline Global cognitive score & NS & $\begin{array}{l}r=-0.51 \\
P=0.0016\end{array}$ & $\begin{aligned} r & =-0.50 \\
P & =0.0023\end{aligned}$ \\
\hline Braak score & $\begin{aligned} r & =-0.35 \\
P & =0.034\end{aligned}$ & $\begin{aligned} r & =0.72 \\
P & <0.0001\end{aligned}$ & $\begin{array}{l}r=0.80 \\
P<0.0001\end{array}$ \\
\hline Reagan diagnosis & $\begin{aligned} r & =-0.57 \\
P & =0.0003\end{aligned}$ & $\begin{aligned} r & =0.68 \\
P & <0.0001\end{aligned}$ & $\begin{aligned} r & =0.71 \\
P & <0.0001\end{aligned}$ \\
\hline CERAD diagnosis & $\begin{aligned} r & =-0.42 \\
P & =0.013\end{aligned}$ & $\begin{aligned} r & =0.58 \\
P & =0.0002\end{aligned}$ & $\begin{aligned} r & =0.58 \\
P & =0.0003\end{aligned}$ \\
\hline
\end{tabular}

NS, not statistically significant; $r$, Spearman rank correlation coefficient.

rons were sparse (Figure 5B, black asterisk), with many of these neurons displaying light immunostaining (Figure $5 \mathrm{~B}$, red arrow). In addition, $\mathrm{NCl}$ TauC3 neuronal staining was either extremely sparse or nonexistent in the CBF
(Figure 5, A and B). As disease severity progressed to $\mathrm{MCl}$, TauC3 immunoreactivity was first seen in the center of the cell cytoplasm in neurons dual stained for pS422 and TauC3 (Figure 5, C and D, black arrow). As tangles
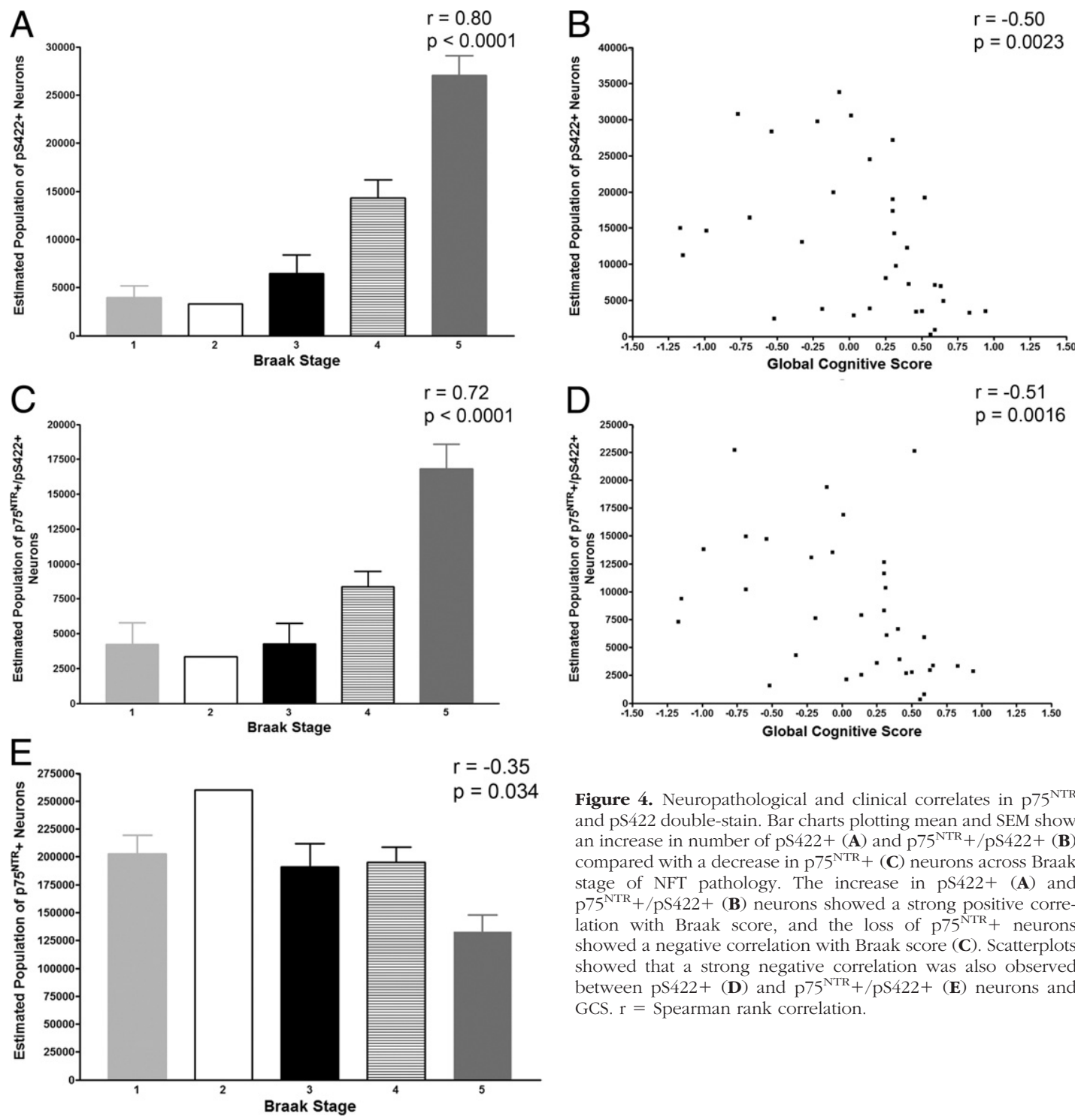

Figure 4. Neuropathological and clinical correlates in p75 and pS422 double-stain. Bar charts plotting mean and SEM show an increase in number of $\mathrm{pS} 422+(\mathbf{A})$ and $\mathrm{p} 75^{\mathrm{NTR}}+/ \mathrm{pS} 422+(\mathbf{B})$ compared with a decrease in $\mathrm{p} 75^{\mathrm{NTR}}+(\mathbf{C})$ neurons across Braak stage of NFT pathology. The increase in $\mathrm{pS} 422+$ (A) and $\mathrm{p} 75^{\mathrm{NTR}}+/ \mathrm{pS} 422+(\mathbf{B})$ neurons showed a strong positive correlation with Braak score, and the loss of $\mathrm{p} 75^{\mathrm{NTR}}+$ neurons showed a negative correlation with Braak score (C). Scatterplots showed that a strong negative correlation was also observed between pS422+ (D) and $\mathrm{p} 75^{\mathrm{NTR}}+/ \mathrm{pS} 422+(\mathbf{E})$ neurons and GCS. $r=$ Spearman rank correlation. 

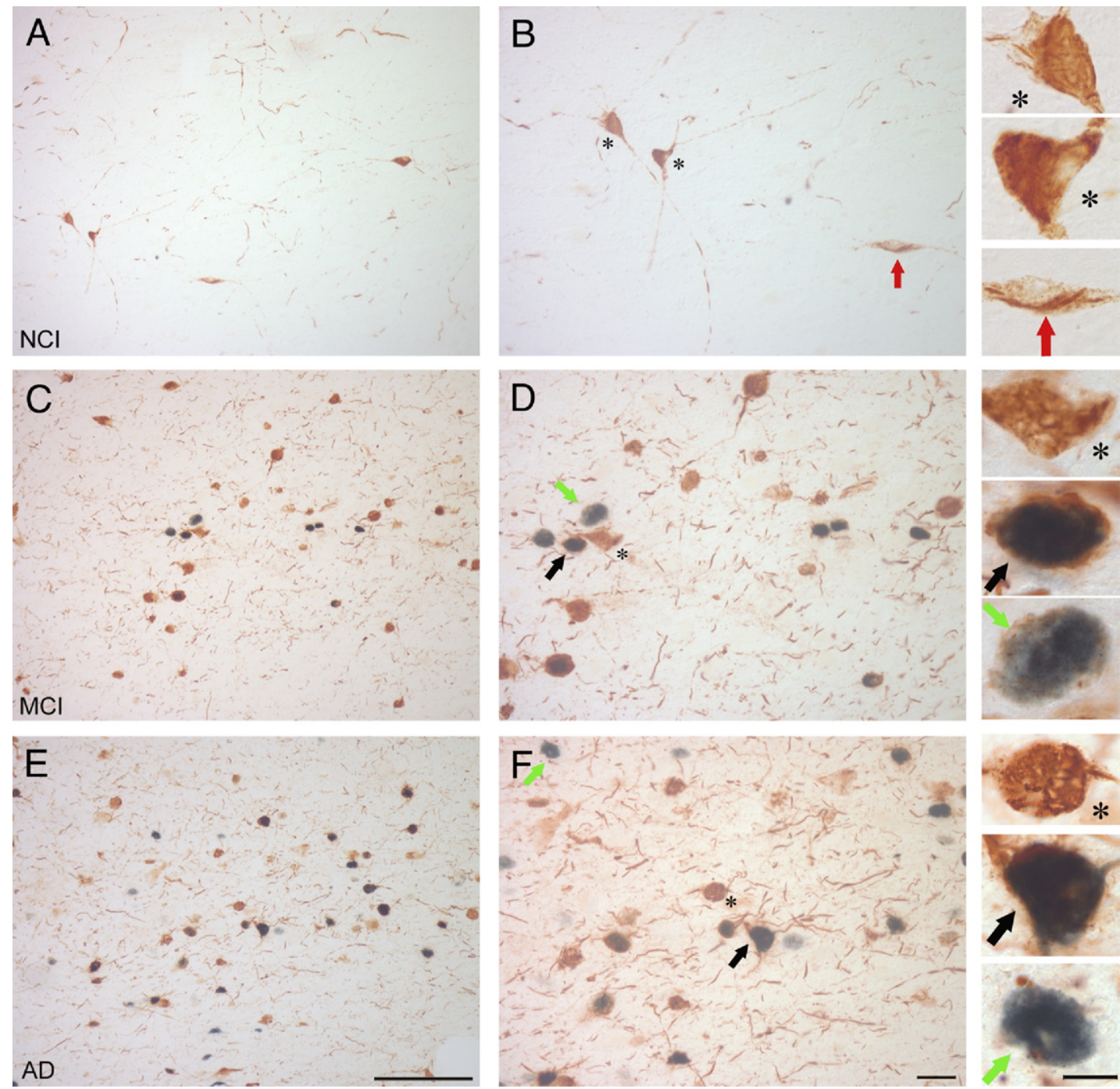

Figure 5. pS422 and TauC3 immunolabeled neurons. NB tissue immunohistochemically stained for pS422+ (brown) and TauC3+ (blue) within the CBF demonstrating an increase the number of pS422+, pS422+/TauC3+, and TauC3+ neurons from NCI (A and $\mathbf{B})$, to MCI $(\mathbf{C}$ and $\mathbf{D})$ and to AD (E and $\mathbf{F})$. In most NCI cases (B), single-label pS422+ neurons were sparse (asterisk), and many pS422 immunoreactive neurons displayed very light staining (red arrow). In MCI (D), there was an increase in pS422+ (asterisk) neurons and the appearance of both pS422+/TauC3+ (black arrow) and TauC3 + neurons (green arrow) In $\mathrm{AD}(\mathbf{F})$, there was an increase in all three neuronal phenotypes for $\mathrm{pS} 422+($ asterisk), pS422+/TauC3+ (black arrow) and TauC3+ (green arrow). Images in A, C, E taken at $\times 10$ and scale bar is $250 \mu \mathrm{m}$. Images in B, D, F were taken at $\times 20$ and scale bar is $50 \mu \mathrm{m}$. Images to the right were taken at $\times 60$ and scale bar is $25 \mu \mathrm{m}$.

continued to mature, neurons were only TauC3 immunopositive and often appeared shrunken or misshapen before becoming a globose tangle in both $\mathrm{MCl}$ and $\mathrm{AD}$ cases (Figure 5, D and F, green arrow).

Stereologic cell counting was used to quantify the number of pS422+, pS422+/TauC3+ and TauC3+ neurons (Table 5). The estimated number of single pS422+ neurons was greater than those dual stained for $\mathrm{p} 75^{\mathrm{NTR}}+/ \mathrm{pS} 422+$. This is most likely due to the lack of a cholinergic cell marker in this double-stain. The increase in number of pS422+ neurons in $\mathrm{MCl}$ and $\mathrm{AD}$ observed in this quantification (Figure $6 \mathrm{~A}$ ) was consistent with the increase in pS422+ neurons in the $\mathrm{p} 75^{\mathrm{NTR}} / \mathrm{pS} 422$ double-stain data (present study). There was also a slight increase in the number of pS422+/TauC3+ in $\mathrm{MCl}$ and $\mathrm{AD}$ (Figure 6B). The number of TauC3+ neurons in the three clinical groups was variable, and no trend could be discerned (Figure 6C).

Next, we converted the number of neurons to percentages of total neurons counted in each case to assess whether the relative proportions of pS422+, pS422+/ TauC3+, and TauC3+ neurons differed across disease stage. We found that the relative proportion of all three neuronal populations remained essentially the same across $\mathrm{NCl}, \mathrm{MCl}$, and AD. Across the three clinical groups, the percentage of pS422+ neurons ranged from $82.2 \%$ to $85.1 \%$, the double-labeled pS422+/TauC3+ neurons ranged from $13.6 \%$ to $15.6 \%$, and the means of the single-label TauC3+ neurons ranged from $1.3 \%$ to $2.1 \%$, comprising a very small proportion of the total number of neurons counted (see Supplemental Table S2 at $h$ ttp://ajp.amjpathol.org). These data suggest that the 
Table 5. Summary of Quantification of $\mathrm{pS} 422+, \mathrm{pS} 422+/ \mathrm{TauC} 3+$ and TauC3 + Neurons

\begin{tabular}{|c|c|c|c|c|}
\hline & \multicolumn{3}{|c|}{ Clinical diagnosis } & \multirow[b]{2}{*}{$P$ value } \\
\hline & $\begin{array}{c}\mathrm{NCl} \\
(N=12)\end{array}$ & $\begin{array}{c}\mathrm{MCl} \\
(N=13)\end{array}$ & $\begin{array}{c}\mathrm{AD} \\
(N=10)\end{array}$ & \\
\hline $\begin{array}{l}\text { Ps422+ }\left(\times 10^{3}\right) \\
\text { Mean } \pm \mathrm{SD} \\
\text { (Range) }\end{array}$ & $\begin{array}{l}22.2 \pm 22.7 \\
(4.4-68.9)\end{array}$ & $\begin{array}{l}36.6 \pm 35.0 \\
(0.6-107.3)\end{array}$ & $\begin{array}{l}45.8 \pm 26.1 \\
(12.6-93.8)\end{array}$ & 0.072 \\
\hline $\begin{array}{l}\text { ps422+/lau-C } 3+\left(\begin{array}{ll}\times & 10\end{array}\right) \\
\text { Mean } \pm \text { SD } \\
\text { (Range) }\end{array}$ & $\begin{array}{c}4.4 \pm 7.2 \\
(0.5-24.4)\end{array}$ & $\begin{array}{c}6.9 \pm 7.8 \\
(0.2-21.3)\end{array}$ & $\begin{array}{r}6.2 \pm 5.7 \\
(0.3-18.6)\end{array}$ & 0.4 \\
\hline $\begin{array}{l}\text { Tau-C3+ }\left(\times 10^{3}\right) \\
\text { Mean } \pm \text { SD } \\
\text { (Range) }\end{array}$ & $\begin{array}{l}0.5 \pm 1.0 \\
(0-3.2)\end{array}$ & $\begin{array}{l}1.3 \pm 2.3 \\
(0.03-8.0)\end{array}$ & $\begin{array}{l}0.7 \pm 0.8 \\
(0-2.6)\end{array}$ & 0.4 \\
\hline
\end{tabular}

*Kruskal-Wallis test.

transition from pS422+ to TauC3+ pathology likely occurs at a constant rate during the progression from $\mathrm{NCl}$ to $\mathrm{MCl}$ and into $\mathrm{AD}$.

\section{Neuropathological and Clinical Correlates}

After quantifying neuronal number for all three cell types, neuronal populations were compared with neuropathological and clinical variables. There was a significant correlation (Table 6) between pS422+ neuron and age $(r=0.49, P=0.0025)$, Braak score $(r=-0.76, P<$ 0.0001; see Supplemental Figure S1A at http://ajp. amjpathol.org), GCS $(r=-0.51, P=0.0016$; see Supplemental Figure S1B at http://ajp.amjpathol.org), and MMSE $(r=-0.40, P=0.018)$. The number of pS422 $+/$ TauC3+ neurons significantly correlated with age $(r=$ $0.41, P=0.015)$, and each of the neuropathological criteria examined including Braak score $(r=0.46, P=$ $0.0055)$ (Table 6). By contrast, TauC3+ neuron numbers were significantly correlated only with Braak stage $(r=$ $0.36, P=0.035$ ) (Table 6). These data indicate that the appearance of pS422 correlated with cognitive decline, whereas the increase in TauC3+ neurons did not.

\section{pS422 Immunoreactive NTs}

Because a growing body of evidence suggests that alterations in tau pathology plays an important role in axonal transport dysfunction, we used stereological methods to quantify pS422+ NTs in the tissue sections immunostained for pS422/TauC3. Numerous pS422+ NTs were present within the CBF in all cases examined (Figure 7A). Quantification of pS422+ NTs demonstrated a trend toward an increase in the length of immunoreactive processes between $\mathrm{MCl}$ and $\mathrm{AD}$ (Figure 7B). The amount of pS422+ NTs was significantly correlated with all neuropathological scores including Braak stage $(r=$ $0.80, P<0.0001$ ) (Figure 7C, Table 6 ) as well as cognitive scores of MMSE $(r=-0.39 ; P=0.019)$ and GCS $(r=-0.40, P=0.018)$ (Figure $7 D$, Table 6). These findings suggest that the tau modifications are indicative of impaired axonal/dendritic processes and perhaps related to an axonal transport defect.

\section{Immunofluorescence of $p 75^{N T R}, p S 422$, and TauC3 CBF Neurons}

Because of the variability in the occurrence of the TauC3 epitope, the question arose as to whether those neurons that were pS422+ or TauC3+ still expressed the cholinergic cell maker, p75 ${ }^{\mathrm{NTR}}$. Sections from select $\mathrm{NCl}, \mathrm{MCl}$ and $A D$ cases were double stained for either $p 75^{\mathrm{NTR}}$ and pS422 or p75 ${ }^{\mathrm{NTR}}$ and TauC3 using immunofluorescence. In general, pS422+ neurons co-labeled with $\mathrm{p} 75^{\mathrm{NTR}}$, and often appeared shrunken and misshapen in $\mathrm{MCl}$ and $\mathrm{AD}$. In $\mathrm{NCl}$ cases, very few neurons displayed pS422 but pS422+ NTs were present within the CBF (Figure 8 A-C). In the $\mathrm{MCl}$ cases, there were many pS422+ neurons, which were also detected with p75 NTR (Figure $8 \mathrm{D}-\mathrm{F}$ ). Double-labeled p75 ${ }^{\mathrm{NTR}}$ and pS422 neurons were also found in AD along with pS422+ NTs (Figure $8 \mathrm{G}-\mathrm{I}$ ).

The $\mathrm{p} 75^{\mathrm{NTR}} / \mathrm{TauC} 3$ double staining was markedly different from that seen in the pS422/p75 NTR dual immunolabeled sections within the CBF neurons. In general, perikarya displaying TauC3 immunoreactivity lacked p75 NTR in each clinical group. In the $\mathrm{NCl}$ cases, there were many p75 ${ }^{\mathrm{NTR}}+\mathrm{NB}$ neurons, but virtually no TauC3 + perikarya (Figure $9 \mathrm{~A}-\mathrm{C}$ ). In the $\mathrm{MCl}$ cases, there were only a few scattered TauC3+ neurons, but there were numerous p75 $75^{\mathrm{NTR}}+$ neurons that did not co-label with the TauC3+ neurons (Figure $9 \mathrm{D}-\mathrm{F}$ ). The $\mathrm{AD}$ cases displayed an increase in TauC3+ NB neurons and a few doublestained neurons; however, most TauC3+ neurons lacked p75 NTR immunoreactivity (Figure 9 G-I). The paucity of TauC3 and p $75^{\text {NTR }}$ double-labeled neurons suggests that the presence of TauC3 is associated with a loss of the cholinergic phenotypic marker p $75^{\mathrm{NTR}}$, likely indicating that TauC3+ neurons are beginning a series of changes that might eventually lead to dysfunction or degeneration.

\section{Discussion}

Degeneration of the CBF correlates with disease duration, disease severity and cognitive impairment in $A D .^{3,5-9,77}$ These neurons develop NFTs consisting of various forms of tau early in the disease process. ${ }^{15,17}$ In the present study, we provide evidence for the onset of intraneuronal tau pathology before frank CBF neuron loss, which cor- 

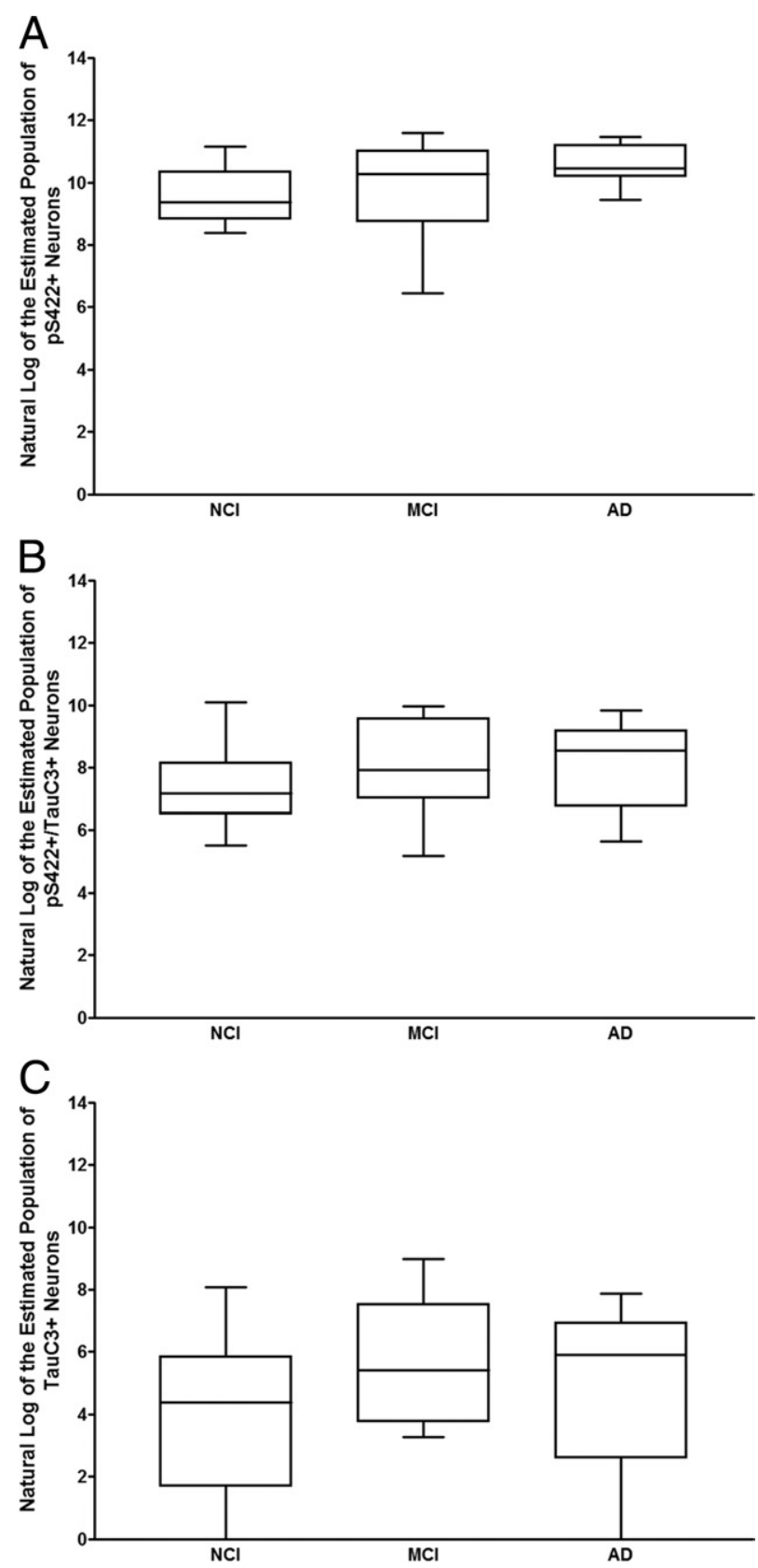

Figure 6. Quantification of pS422 and TauC3 double-stain. Box plots showing an increase in the number of pS422+ neurons (A) and pS422+/TauC3+ neurons (B) in MCI and AD. C: Appearance of TauC3+ neurons was variable across the cognitive diagnosis groups.

relates with neuropathological criteria and tests of cognitive function. We found that a decrease in the number of NB cholinergic neurons expressing the low-affinity p75 ${ }^{\text {NTR }}$ receptor, an excellent marker of CBF neurons, ${ }^{14}$ was paralleled by an increase in pS422+ neurons. The pS422 antibody identifies phosphorylation of Serine 422 on the tau molecule, which has been established as an early event during NFT evolution. ${ }^{30,32}$ Cells containing the pS422 epitope can eventually transition to TauC3+ neurons indicating the onset of NFT formation, ${ }^{32}$ and here we demonstrate that TauC3 is associated with a phenotypic loss of $p 75^{N T R}$. Our findings indicated that CBF neurons that display the pretangle marker pS422 but not TauC3 correlate with the cognitive decline observed in $\mathrm{MCl}$ and $\mathrm{AD}$. These data indicate that development of pretangle events in the NB neurons in the CBF may be a mechanistic cellular lesion that affects the onset of cognitive impairment before frank NFT deposition of AD.

\section{Increase in Intraneuronal Phosphorylation of Tau (pS422) and Loss of p75 ${ }^{\text {NTR }}$ during $A D$ Progression}

Cholinergic phenotypic markers such as ChAT, and the NGF receptors $\mathrm{p} 75^{\mathrm{NTR}}$ and TrkA, are differentially affected during the progression of $A D .{ }^{77}$ For example, there is a significant decrease in the number of p75 NTR and TrkA positive neurons within the NB of subjects with $\mathrm{MCl}$ and mild $\mathrm{AD}$ compared with $\mathrm{NCl},{ }^{13,14}$ but there is not a significant loss of ChAT containing neurons, ${ }^{38}$ suggesting a neurotrophic defect early in the disease process. The development of neurotrophic degenerative events appears to coincide with the accumulation of tau pathology in these neurons early in the disease process. ${ }^{15-17,78}$ In this regard, ChAT immunopositive neurons within the NB also contain the early tau pathological markers AT8 or Alz50 in $\mathrm{NCl}$ and $\mathrm{MCl}^{17}$

In the present study, we examined whether the appearance of an early pretangle pathological event, identified by pS422, was associated with a reduction in CBF perikarya. Stereological quantification demonstrated a significant loss of $\mathrm{p} 75^{\mathrm{NTR}}+$, with an increase in $\mathrm{p} 75^{\mathrm{NTR}}+1$ pS422+ and pS422+ neurons between NCl and AD but not $\mathrm{MCl}$. These findings are consistent with the postulate that $\mathrm{MCl}$ represents a transitional state between normal aging and $A D .^{75,76}$ In addition, there was a significant relationship between the decrease in $p 75^{\mathrm{NTR}}+$ and the increase in both p $75^{\mathrm{NTR}}+/ \mathrm{pS} 422+$ and pS422+ neurons and Braak scores, NIA-Reagan diagnosis, and CERAD, suggesting that the extent of cortical $A D$ pathological lesions found in the areas forming the medial temporal lobe memory circuit correlates with a decline in p $75^{\text {NTR }}+$ and an increase in pS422+ neurons in the NB. We also found a significant correlation between double and single-labeled pS422 neurons with MMSE and GCS, suggesting that the onset of pretangle immunoreactivity within NB cholinergic neurons is an early pathological event, which plays a mechanistic role in the progression of cognitive decline and the eventual formation of filamentous NFT pathology in these neurons.

\section{NFT Formation in the CBF Is Slower than in Other Cortical Regions}

Previous studies have examined some tau modifications within the CBF. For example, studies using the Gallyas silver stain and AT8 immunoreactivity demonstrated NFTs within NB neurons as early as Braak stage I or II. ${ }^{15}$ The present study used a series of site-specific tau antibodies directed at different stages of tau pathology to mark the evolution of NFTs within cholinergic neurons of the NB. These antibodies were previously used in a re- 
Table 6. Clinical and Neuropathological Correlations with Number of pS422+, pS422+/TauC3+, and TauC3+ Neurons

\begin{tabular}{|c|c|c|c|c|}
\hline & pS422+ only & pS422+/Tau-C3+ & Tau-C3+ only & pS422+ NT length \\
\hline Age at death & $\begin{aligned} r & =0.49 \\
(P & =0.0025)\end{aligned}$ & $\begin{aligned} r & =0.41 \\
(P & =0.015)\end{aligned}$ & $\begin{aligned} r & =0.30 \\
(P & =0.075)\end{aligned}$ & $\begin{aligned} r & =0.41 \\
(P & =0.016)\end{aligned}$ \\
\hline MMSE & $\begin{aligned} r & =-0.40 \\
(P & =0.018)\end{aligned}$ & NS & NS & $\begin{array}{r}r=-0.39 \\
(P=0.019)\end{array}$ \\
\hline Global cognitive score & $\begin{array}{c}r=-0.51 \\
(P=0.0016)\end{array}$ & NS & NS & $\begin{aligned} r & =-0.40 \\
(P & =0.018)\end{aligned}$ \\
\hline Braak score & $\begin{aligned} r & =0.76 \\
(P & <0.0001)\end{aligned}$ & $\begin{aligned} r & =0.46 \\
(P & =0.0055)\end{aligned}$ & $\begin{aligned} r & =0.36 \\
(P & =0.035)\end{aligned}$ & $\begin{aligned} r & =0.80 \\
(P & <0.0001)\end{aligned}$ \\
\hline Reagan diagnosis & $\begin{aligned} r & =0.66 \\
(P & <0.0001)\end{aligned}$ & $\begin{aligned} r & =0.36 \\
(P & =0.034)\end{aligned}$ & NS & $\begin{aligned} r & =0.58 \\
(P & =0.0002)\end{aligned}$ \\
\hline CERAD diagnosis & $\begin{aligned} r & =0.54 \\
(P & =0.0008)\end{aligned}$ & $\begin{aligned} r & =0.40 \\
(P & =0.016)\end{aligned}$ & NS & $\begin{aligned} r & =0.40 \\
(P & =0.016)\end{aligned}$ \\
\hline
\end{tabular}

NS, not statistically significant; $r$, Spearman rank correlation coefficient.

port by our group that studied tangle evolution in the medial temporal cortex. ${ }^{32}$ The evolution of tau pathology is marked by a set of modifications (eg, phosphorylations and truncations) that progress linearly in neurons of the entorhinal cortex, hippocampus, and temporal cortex in AD. ${ }^{27-32}$ Specifically, the early phosphorylation event at serine 422 (identified by the pS422 antibody) is followed by the truncation at the caspase cleavage sight, aspartic acid 421 (identified by the TauC3 antibody). ${ }^{30,32}$ In the medial temporal lobe, there is a much greater proportion of pS422 labeled neurons compared with TauC3 in cases designated as Braak stages I and II. ${ }^{32}$ During disease progression, the amount of TauC3+ neurons steadily increases and the proportion of pS422+ to TauC3 neurons eventually becomes equal in the medial temporal lobe as the disease becomes more severe. ${ }^{32}$ In contrast, within the CBF the percentage of pS422+, pS422+/TauC3+, and TauC3+ neurons remained consistent during the progression of $A D$, suggesting the tangle formation within the NB occurs at a slower rate compared with the medial temporal lobe. The increase in the number of pS422+/ TauC3+ and TauC3+ neurons was significantly related to neuropathological criteria, but not cognitive measures. Moreover, immunofluoresence demonstrated that in neurons where NFTs have begun to coalesce, indicated by TauC3 reactivity, p75 ${ }^{\mathrm{NTR}}$ staining is reduced. This further suggests a dysregulation of NGF receptor activity within the NB neurons at an early stage of NFT formation. Based
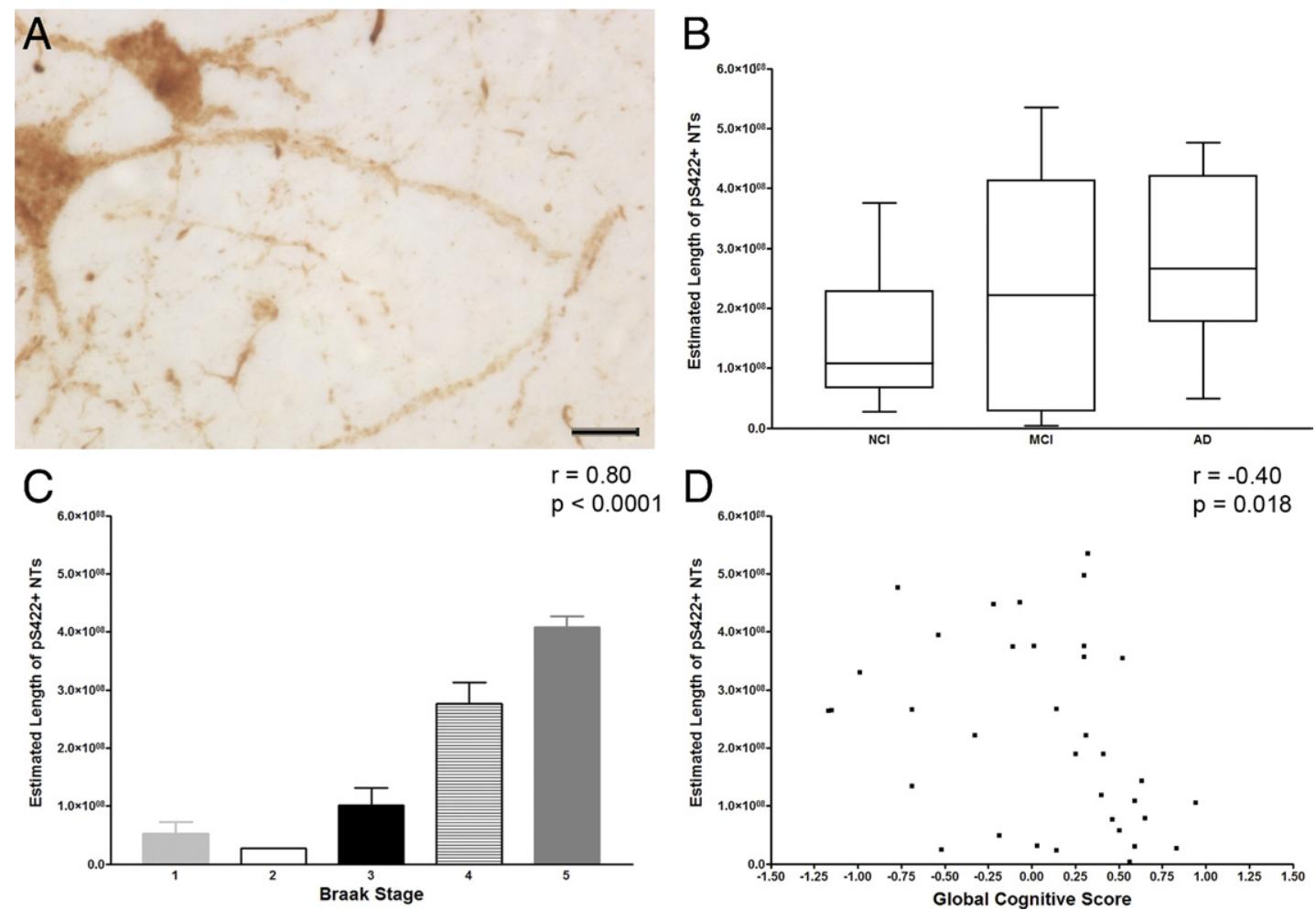

Figure 7. Quantification and correlations of pS422+ NT length. Photomicrograph showing an example of pS422+ NTs within the NB in an AD case (A) Scale bar $=25 \mu \mathrm{m}$. The box plots demonstrate an increase in pS422+ NT length in MCI and AD (B). C: Bar chart plotting mean and SEM shows that the increase in NT length significantly correlated with severity of Braak stage. D: Scatterplot showing a significant negative correlation between GCS and pS422+ thread length. 

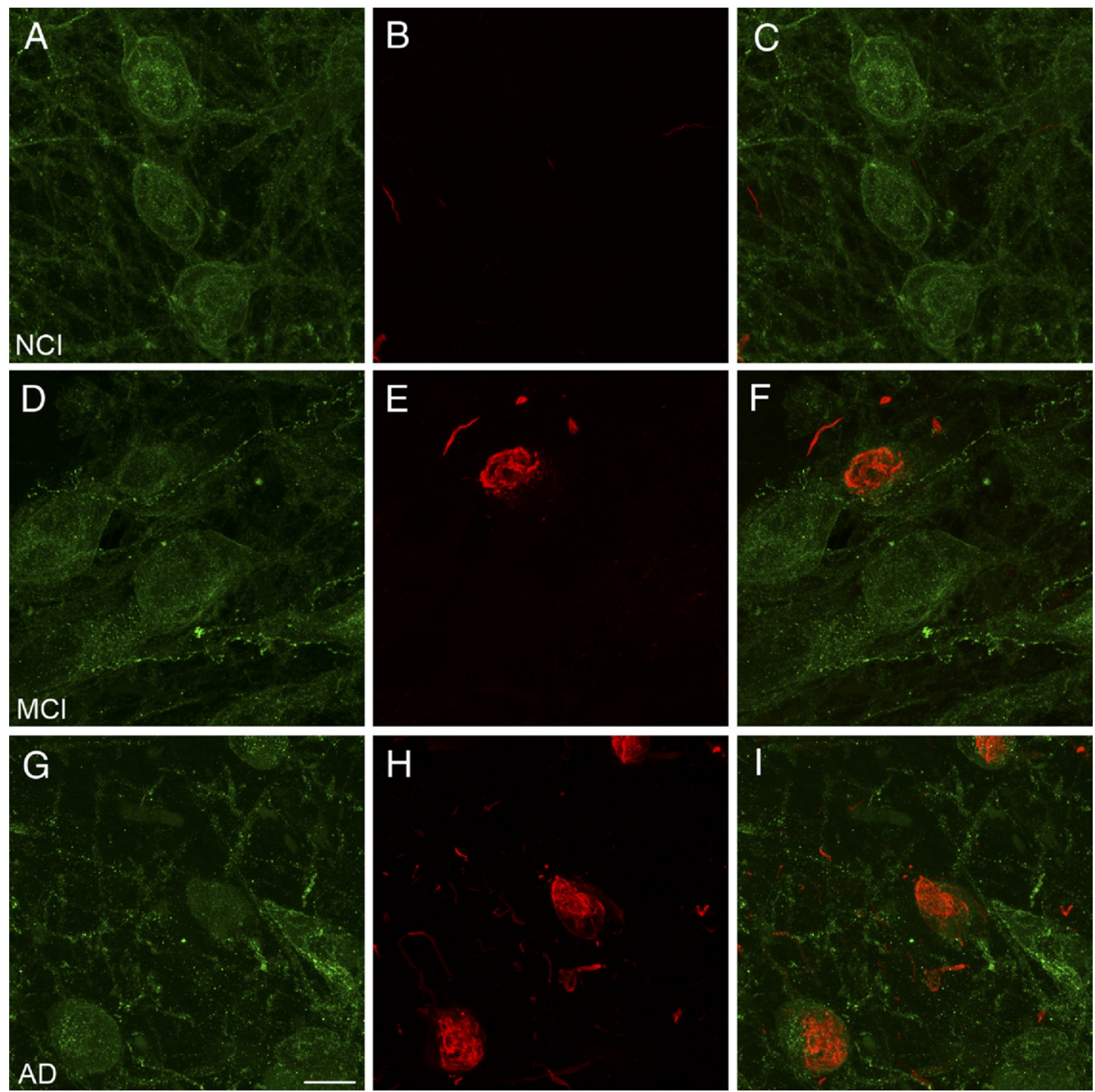

Figure 8. Dual immunofluoresence of $\mathrm{p} 75^{\mathrm{NTR}}$ and pS422. Immunofluoresence of $\mathrm{p} 75^{\mathrm{NTR}}+$ (green) and pS422+ (red) neurons in the NB revealed a large number of p $75^{\mathrm{NTR}}+$ neurons $(\mathbf{A})$ and pS422+ NTs $(\mathbf{B})$ most commonly seen in NCI cases (A-C). In MCI, p $75^{\mathrm{NTR}}+$ neurons $(\mathbf{D})$ were also labeled with pS422 (E and $\left.\mathbf{F}\right)$ In $\mathrm{AD}, \mathrm{p} 75^{\mathrm{NTR}}+$ neurons were still seen $(\mathbf{G})$, but there was an increase in the number of ps422+ neurons $(\mathbf{H})$ that co-labeled with p $75^{\mathrm{NTR}}(\mathbf{I})$. All images taken at magnification $\times 63$. Scale bar $=25 \mu \mathrm{m}$.

on these data, it appears that NFT formation within the CBF evolves at a different rate than in medial temporal lobe structures, and that pretangle events as opposed to more advanced tau aggregation correlates more closely with the cognitive decline.

\section{Tau Modifications First Appear in Neuronal Processes}

In addition to studying the onset of cholinergic NB tau pathology, we also quantified the formation of NTs (ie, tau pathology in dendrites and axons) within the CBF of $\mathrm{NCl}, \mathrm{MCl}$, and $\mathrm{AD}$ cases. NTs are one of the earliest manifestations of tau pathology. ${ }^{28,36}$ Previous studies revealed that the cortical projecting axons and dendrites of the cholinergic NB neurons display a swollen and bulbous appearance during disease progression $^{34}$; however, local changes in axonal process within the CBF were not evaluated. Our data represent the first quantitative clinicopathological analysis of NTs within the CBF across different phases of the disease. We found that NT length increased among cases in $\mathrm{MCl}$ and $\mathrm{AD}$ cases, and that this increase correlated with both neuropathological and clinical variables. The magnitude of NT length compared with the number of pretangle and NFTs suggests that axonal and dendritic processes undergo pathogenesis before the soma of NB neurons. NTs within cholinergic neuritic processes indicate that tau modifications could alter the axonal transport mechanism within the cholinergic cortical innervation sites arising from the NB and ultimately change the integrity of the cholinergic synapses. These clinicopathological data highlight the importance of studying not only tau modifications in neuron somata but changes to their neuritic processes as these may be the earliest pathological lesions. 

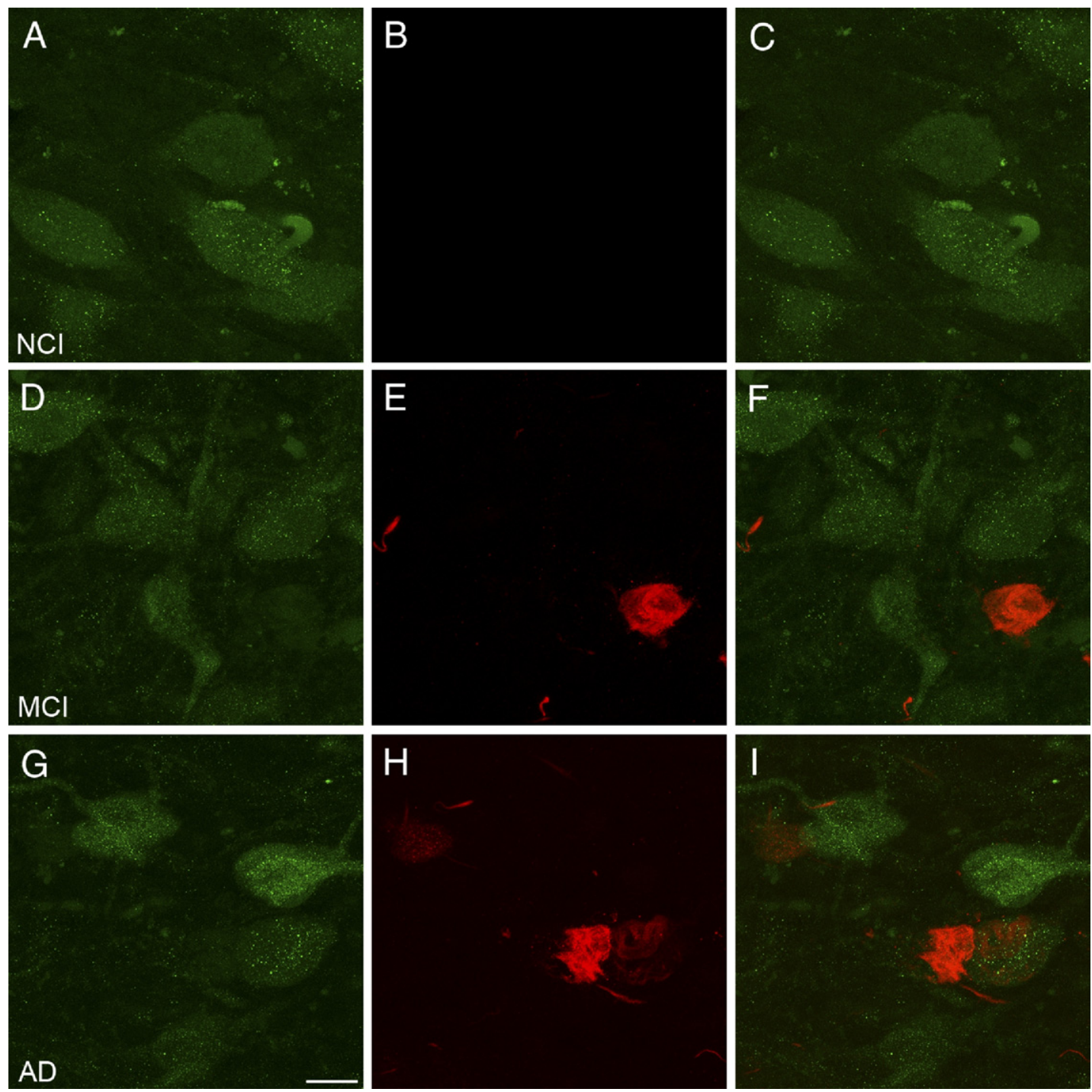

Figure 9. $\mathrm{p} 75^{\mathrm{NTR}}$ and $\mathrm{TauC} 3$ do not colocalize. $\mathrm{p} 75^{\mathrm{NTR}}+$ (green) and $\mathrm{TauC3}+$ (red) immunofluorescence within the NB revealed that most neurons were p $75^{\mathrm{NTR}}+(\mathbf{A})$. Virtually no TauC3+ neurons $(\mathbf{B}$ and $\mathbf{C})$ were found in NCI. In MCI, there were many p $75^{\mathrm{NTR}}+$ neurons $(\mathbf{D})$ and the appearance of, TauC3 + neurons (E) that did not colocalize with $\mathrm{p} 75^{\mathrm{NTR}}(\mathbf{F})$. In AD, $\mathrm{p} 75^{\mathrm{NTR}}+$ neurons were still present $(\mathbf{G})$ but there were many more TauC3 + neurons $(\mathbf{H})$. In most cases, TauC3 + cells lacked $\mathrm{p} 75^{\mathrm{NTR}}$ reactivity (I). All images taken at magnification $\times 63$. Scale bar $=25 \mu \mathrm{m}$.

\section{Discrepancy between Clinical Diagnosis and Neuropathological Score}

Several studies have noted disparities between cognitive diagnoses and $A D$ neuropathology. ${ }^{75,76}$ In the present study, we also observed that several $\mathrm{NCl}$ and $\mathrm{MCl}$ cases had higher Braak scores and NIA Reagan diagnoses than expected. It is perhaps not surprising that the strong and robust association between markers (such as p $75^{\mathrm{NTR}}+$ or pS422+) and neuropathological scores are not always observed in the association with clinical diagnosis. This difference may, in part, be related to the observation that several $\mathrm{NCl}$ and $\mathrm{MCl}$ cases had higher Braak scores and NIA Reagan diagnoses than expected, likely introducing a degree of variability in our analyses. Nevertheless, it is critical to study these outliers as they may provide insight into the ability of some patients to maintain cognitive capability in the presence of a signif- icant pathological load. ${ }^{75,76}$ A comparison between these cases and those that have a similar pathological load but a diagnosis of $A D$ may help differentiate factors crucial to cognitive function from those less directly applicable, such as cognitive reserve or neuroplasticity. ${ }^{79}$

The pathological variability found in the $\mathrm{MCl}$ cases may also have been a reason that the increase in specific tau inclusions did not significantly differ among clinical diagnosis. $\mathrm{MCl}$ is characterized by the presence of memory deficits that are not severe enough to curtail activities of daily living or to meet the criteria for dementia, ${ }^{80}$ but that are considered to represent a prodromal stage of AD. ${ }^{81,82}$ Different types of $\mathrm{MCl}$ are defined by the individual's symptoms and are usually classified as amnestic or nonamnestic $\mathrm{MCl}$. Amnestic $\mathrm{MCl}$ presents with memory loss as the predominant symptom, and individuals diagnosed as amnestic $\mathrm{MCl}$ are at a higher risk for conversion to $A D$ compared with individuals with nonamnes- 
tic $\mathrm{MCl}$. The cases used in this study included four amnestic and nine nonamnestic $\mathrm{MCl}$ cases, and in evaluating the data it was found that the amnestic $\mathrm{MCl}$ cases had a greater number of pS422+ and TauC3+ neurons as well as fewer p $75^{\mathrm{NTR}}+$ neurons. However, this difference between neuron number and amnestic versus nonamnestic $\mathrm{MCl}$ was not significant (data not shown), perhaps because of the small sample size when the $\mathrm{MCl}$ group was subdivided. In addition, we found a significant increase in $\mathrm{p} 75^{\mathrm{NTR}}+/ \mathrm{pS} 422+$ and a decrease in $\mathrm{p} 75^{\mathrm{NTR}}+$ neurons between $\mathrm{NCl}$ and $\mathrm{AD}$, but not between $\mathrm{MCl}$. For these reasons, it might be important to use more $\mathrm{MCl}$ cases or limit the study to amnestic $\mathrm{MCl}$ cases, as this could elucidate a significant difference among the three clinical stages, namely, $\mathrm{NCl}, \mathrm{MCl}$, and $A D$, in future studies.

\section{Conclusions}

The present study identified changes in the evolution of tau pathology with the $\mathrm{CBF}$ during the progression from $\mathrm{NCl}$ to $\mathrm{MCl}$ and $\mathrm{AD}$. We discovered that the appearance of pS422, an early marker of tau pathology, occurred with a concomitant decrease in $p 75^{\mathrm{NTR}}$ within the neurons of the NB. Quantitative analysis revealed a positive correlation between the number of pS422+ neurons and neuropathological and cognitive assessments indicating that pretangle tau modifications occur coincident with cognitive decline. Second, when comparing the development of NFT pathology based on the appearance of the pretangle marker pS422 and the later formed tau epitope, TauC3 to that described in the medial temporal lobe, ${ }^{32}$ NFT formation in the NB is a more protracted process. This suggests that tangles develop at different rates depending on the site of pathology during the onset of dementia. In addition, the absence of $p 75^{\text {NTR }}$ in NB cells immunoreactive for TauC3 indicates that tau dysfunction in these neurons occurs before the onset of NFT deposition. In the future, work to determine whether a specific tau modification exists that disrupts cholinergic function or initiates apoptotsis is critical to gaining a better understanding of NB neuron dysfunction in AD. Lastly, the quantification of pS422 NTs within the CBF indicates tau modifications occur within neuronal processes coursing within the neuropil before their appearance within NB perikarya. More interesting is the observation that the increases in pS422+ NT length correlates with neuropathology and cognitive decline. This suggests that neuronal dysfunction and eventual degeneration may begin in the axons and dendrites perhaps disrupting transport and/or synaptic process affecting cholinergic signal transduction

\section{Acknowledgments}

We are indebted to the altruism and support of the participants in the Religious Orders Study. We also thank the Northwestern University Cell Imaging Facility for training and allowing us access to the Zeiss LSM 510 Meta laser scanning confocal microscope. We also thank Andres Silva and Muhammad Nadeem for technical assistance.

\section{References}

1. Mesulam MM, Mufson EJ, Levey Al, Wainer $\mathrm{BH}$ : Cholinergic innervation of cortex by the basal forebrain: cytochemistry and cortical connections of the septal area, diagonal band nuclei, nucleus basalis (substantia innominata), and hypothalamus in the rhesus monkey. J Comp Neurol 1983, 214:170-197

2. Mesulam MM, Geula C: Nucleus basalis (Ch4) and cortical cholinergic innervation in the human brain: observations based on the distribution of acetylcholinesterase and choline acetyltransferase. J Comp Neurol 1988, 275:216-240

3. Wilcock GK, Esiri MM: Plaques, tangles and dementia. A quantitative study. J Neurol Sci 1982, 56:343-356

4. Bierer LM, Haroutunian V, Gabriel S, Knott PJ, Carlin LS, Purohit DP, Perl DP, Schmeidler J, Kanof P, Davis KL: Neurochemical correlates of dementia severity in Alzheimer's disease: relative importance of the cholinergic deficits. J Neurochem 1995, 64:749-760

5. Whitehouse PJ, Price DL, Struble RG, Clark AW, Coyle JT, Delon MR Alzheimer's disease and senile dementia: loss of neurons in the basal forebrain. Science 1982, 215:1237-1239

6. McGeer PL, McGeer EG, Suzuki J, Dolman CE, Nagai T: Aging Alzheimer's disease, and the cholinergic system of the basal forebrain. Neurology 1984, 34:741-745

7. Tagliavini F, Pilleri G: Neuronal counts in basal nucleus of Meynert in Alzheimer disease and in simple senile dementia. Lancet 1983, 1:469-470

8. Arendt T, Bigl V, Tennstedt A, Arendt A: Neuronal loss in different parts of the nucleus basalis is related to neuritic plaque formation in cortical target areas in Alzheimer's disease. Neuroscience 1985 14:1-14

9. Mufson EJ, Bothwell M, Kordower JH: Loss of nerve growth factor receptor-containing neurons in Alzheimer's disease: a quantitative analysis across subregions of the basal forebrain. Exp Neurol 1989 , 105:221-232

10. Hefti F: Is Alzheimer disease caused by lack of nerve growth factor? Ann Neurol 1983, 13:109-110

11. Teng KK, Hempstead BL: Neurotrophins and their receptors: signaling trios in complex biological systems. Cell Mol Life Sci 2004, 61: 35-48

12. Kaplan DR, Miller FD: Neurotrophin signal transduction in the nervous system. Curr Opin Neurobiol 2000, 10:381-391

13. Mufson EJ, Ma SY, Cochran EJ, Bennett DA, Beckett LA, Jaffar S, Saragovi HU, Kordower $\mathrm{JH}$ : Loss of nucleus basalis neurons containing trkA immunoreactivity in individuals with mild cognitive impairment and early Alzheimer's disease. J Comp Neurol 2000, 427:19-30

14. Mufson EJ, Ma SY, Dills J, Cochran EJ, Leurgans S, Wuu J, Bennett DA, Jaffar S, Gilmor ML, Levey Al, Kordower JH: Loss of basal forebrain P75(NTR) immunoreactivity in subjects with mild cognitive impairment and Alzheimer's disease. J Comp Neurol 2002, 443:136153

15. Sassin I, Schultz C, Thal DR, Rub U, Arai K, Braak E, Braak H: Evolution of Alzheimer's disease-related cytoskeletal changes in the basal nucleus of Meynert. Acta Neuropathol (Berl) 2000, 100:259 269

16. Wu CK, Thal L, Pizzo D, Hansen L, Masliah E, Geula C: Apoptotic signals within the basal forebrain cholinergic neurons in Alzheimer's disease. Exp Neurol 2005, 195:484-496

17. Mesulam M, Shaw $P$, Mash D, Weintraub S: Cholinergic nucleus basalis tauopathy emerges early in the aging-MCI-AD continuum. Ann Neurol 2004, 55:815-828

18. Johnson GVW, Hartigan JA: Tau protein in normal and Alzheimer's disease brain: an update. Alzheimer Dis Rev 1998, 3:125-141

19. Buee L, Bussiere T, Buee-Scherrer V, Delacourte A, Hof PR: Tau protein isoforms, phosphorylation and the role in neurodegenerative disorders. Brain Res Brain Res Rev 2000, 33:95-130

20. Spillantini MG, Goedert M: Tau protein pathology in neurodegenerative diseases. Trends Neurosci 1998, 21:428-433 
21. Arriagada PV, Growdon JH, Hedley-Whyte ET, Hyman BT: Neurofibrillary tangles but not senile plaques parallel duration and severity of Alzheimer's disease. Neurology 1992, 42:631-639

22. Braak H, Braak E: Neuropathological stageing of Alzheimer-related changes. Acta Neuropathol 1991, 82:239-259

23. Grundke-labal I, Iqbal K, Tung YC, Quinlan M, Wisniewski HM, Binder LI: Abnormal phosphorylation of the microtubule-associated protein tau (tau) in Alzheimer cytoskeletal pathology. Proc Natl Acad Sci USA: 1986, 83:4913-4917

24. Wood JG, Mirra SS, Pollock NJ, Binder LI: Neurofibrillary tangles of Alzheimer disease share antigenic determinants with the axonal microtubule-associated protein tau (tau) [published erratum appears in Proc Natl Acad Sci USA 1986;83:9773]. Proc Natl Acad Sci USA 1986, 83:4040-4043

25. Alonso AC, Grundke-lqbal I, Iqbal K: Alzheimer's disease hyperphosphorylated tau sequesters normal tau into tangles of filaments and disassembles microtubules. Nat Med 1996, 2:783-787

26. Gamblin TC, Chen F, Zambrano A, Abraha A, Lagalwar S, Guillozet $A L$, Lu M, Fu Y, Garcia-Sierra F, LaPointe N, Miller R, Berry RW, Binder LI, Cryns VL: Caspase cleavage of tau: linking amyloid and neurofibrillary tangles in Alzheimer's disease. Proc Natl Acad Sc USA: 2003, 100:10032-10037

27. Ghoshal N, Garcia-Sierra F, Fu Y, Beckett LA, Mufson EJ, Kuret J, Berry RW, Binder LI: Tau-66: evidence for a novel tau conformation in Alzheimer's disease. J Neurochem 2001, 77:1372-1385

28. Ghoshal N, Garcia-Sierra F, Wuu J, Leurgans S, Bennett DA, Berry RW, Binder LI: Tau conformational changes correspond to impairments of episodic memory in mild cognitive impairment and Alzheimer's disease. Exp Neurol 2002, 177:475-493

29. Garcia-Sierra F, Ghoshal N, Quinn B, Berry RW, Binder LI: Conformational changes and truncation of tau protein during tangle evolution in Alzheimer's disease. J Alzheimer's Dis 2003, 5:65-77

30. Guillozet-Bongaarts AL, Garcia-Sierra F, Reynolds MR, Horowitz PM, Fu Y, Wang T, Cahill ME, Bigio EH, Berry RW, Binder LI: Tau truncation during neurofibrillary tangle evolution in Alzheimer's disease. Neurobiol Aging 2005, 26:1015-1022

31. Binder LI, Guillozet-Bongaarts AL, Garcia-Sierra F, Berry RW: Tau, tangles, and Alzheimer's disease. Biochim Biophys Acta 2005, 1739 : $216-223$

32. Guillozet-Bongaarts AL, Cahill ME, Cryns VL, Reynolds MR, Berry RW, Binder LI: Pseudophosphorylation of tau at serine422 inhibits caspase cleavage: in vitro evidence and implications for tangle formation in vivo. J Neurochem 2006, 97:1005-1014

33. Guillozet-Bongaarts AL, Glajch KE, Libson EG, Cahill ME, Bigio E, Berry RW, Binder LI: Phosphorylation and cleavage of tau in non-AD tauopathies. Acta Neuropathol 2007, 113:513-520

34. Geula C, Nagykery N, Nicholas A, Wu CK: Cholinergic neuronal and axonal abnormalities are present early in aging and in Alzheimer disease. J Neuropathol Exp Neurol 2008, 67:309-318

35. LaPointe NE, Morfini G, Pigino G, Gaisina IN, Kozikowski AP, Binder LI, Brady ST: The amino terminus of tau inhibits kinesin-dependent axonal transport: implications for filament toxicity. J Neurosci Res 2009, 87:440-451

36. Su JH, Deng G, Cotman CW: Transneuronal degeneration in the spread of Alzheimer's disease pathology: immunohistochemical evidence for the transmission of tau hyperphosphorylation. Neurobiol Dis 1997, 4:365-375

37. Mufson EJ, Chen EY, Cochran EJ, Beckett LA, Bennett DA, Kordower $\mathrm{JH}$ : Entorhinal cortex beta-amyloid load in individuals with mild cognitive impairment. Exp Neurol 1999, 158:469-490

38. Gilmor ML, Erickson JD, Varoqui H, Hersh LB, Bennett DA, Cochran EJ, Mufson EJ, Levey Al: Preservation of nucleus basalis neurons containing choline acetyltransferase and the vesicular acetylcholine transporter in the elderly with mild cognitive impairment and early Alzheimer's disease. J Comp Neurol 1999, 411:693-704

39. Kordower JH, Chu Y, Stebbins GT, DeKosky ST, Cochran EJ, Bennett $D$, Mufson EJ: Loss and atrophy of layer II entorhinal cortex neurons in elderly people with mild cognitive impairment. Ann Neurol 2001 , 49:202-213

40. Bennett DA, Shannon KM, Beckett LA, Goetz CG, Wilson RS: Metric properties of nurses' ratings of parkinsonian signs with a modified Unified Parkinson's Disease Rating Scale. Neurology 1997, 49:15801587
41. Bennett DA, Shannon KM, Beckett LA, Wilson RS: Dimensionality of parkinsonian signs in aging and Alzheimer's disease. J Gerontol A Biol Sci Med Sci 1999, 54:M191-M196

42. Goodglass H, Kaplan E: The assessment of aphasia and related disorders. Philadelphia, Lea \& Febiger, 1972, pp vii

43. Ekstrom RB, Harman $\mathrm{HH}$ : Manual for kit of factor-referenced cognitive tests, 1976. Princeton, NJ, Educational Testing Service, 1976, p. v

44. Benton AL, Varney NR, Hamsher KD: Visuospatial judgment. A clinical test. Arch Neurol 1978, 35:364-367

45. Morris JC, Heyman A, Mohs RC, Hughes JP, van Belle G, Fillenbaum G, Mellits ED, Clark C: The Consortium to Establish a Registry for Alzheimer's Disease (CERAD). Part I: clinical and neuropsychologica assessment of Alzheimer's disease. Neurology 1989, 39:1159-1165

46. Albert M, Smith LA, Scherr PA, Taylor JO, Evans DA, Funkenstein HH Use of brief cognitive tests to identify individuals in the community with clinically diagnosed Alzheimer's disease. Int J Neurosci 1991 57:167-178

47. Willshire D, Kinsella G, Prior M: Estimating WAIS-R IQ from the National Adult Reading Test: a cross-validation. J Clin Exp Neuropsychol 1991, 13:204-216

48. Welsh KA, Butters N, Hughes JP, Mohs RC, Heyman A: Detection and staging of dementia in Alzheimer's disease. Use of the neuropsychological measures developed for the Consortium to Establish a Registry for Alzheimer's Disease. Arch Neurol 1992, 49:448-452

49. Cooper JA, Sagar HJ: Incidental and intentional recall in Parkinson's disease: an account based on diminished attentional resources. J Clin Exp Neuropsychol 1993, 15:713-731

50. Pittman J, Andrews $H$, Tatemichi T, Link B, Struening E, Stern $Y$, Mayeux R: Diagnosis of dementia in a heterogeneous population. A comparison of paradigm-based diagnosis and physician's diagnosis. Arch Neurol 1992, 49:461-467

51. Snowdon DA, Kemper SJ, Mortimer JA, Greiner LH, Wekstein DR, Markesbery WR: Linguistic ability in early life and cognitive function and Alzheimer's disease in late life. Findings from the Nun Study. JAMA 1996, 275:528-532

52. McKhann G, Drachman D, Folstein M, Katzman R, Price D, Stadlan EM: Clinical diagnosis of Alzheimer's disease: report of the NINCDSADRDA Work Group under the auspices of Department of Health and Human Services Task Force on Alzheimer's Disease. Neurology 1984, 34:939-944

53. Rubin EH, Morris JC, Grant EA, Vendegna T: Very mild senile dementia of the Alzheimer type. I Clinical assessment. Arch Neurol 1989, 46:379-382

54. Flicker C, Ferris SH, Reisberg B: Mild cognitive impairment in the elderly: Predictors of dementia. Neurology 1991, 41:1006-1009

55. Petersen RC, Smith GE, Ivnik RJ, Tangalos EG, Schaid DJ, Thibodeau SN, Kokmen E, Waring SC, Kurland LT: Apolipoprotein E status as a predictor of the development of Alzheimer's disease in memoryimpaired individuals. JAMA 1995, 273:1274-1278

56. Devanand DP, Folz M, Gorlyn M, Moeller JR, Stern Y: Questionable dementia: clinical course and predictors of outcome. J Am Geriatr Soc 1997, 45:321-328

57. Cochran EJ, Fox JH, Mufson EJ: Severe panencephalic Pick's disease with Alzheimer's disease-like neuropil threads and synaptophysin immunoreactivity. Acta Neuropathol 1994, 88:479-484

58. Mirra SS, Heyman A, McKeel D, Sumi SM, Crain BJ, Brownlee LM, Vogel FS, Hughes JP, van Belle G, Berg L: The Consortium to Establish a Registry for Alzheimer's Disease (CERAD). Part II: Standardization of the neuropathologic assessment of Alzheimer's disease. Neurology 1991, 41:479-486

59. Kins S, Crameri A, Evans DR, Hemmings BA, Nitsch RM, Gotz J: Reduced protein phosphatase 2A activity induces hyperphosphorylation and altered compartmentalization of tau in transgenic mice. J Biol Chem 2001, 276:38193-38200

60. Hasegawa M, Jakes R, Crowther RA, Lee VM, Ihara Y, Goedert M: Characterization of mAb AP422, a novel phosphorylation-dependent monoclonal antibody against tau protein. FEBS Lett 1996, 384:25-30

61. Reynolds $\mathrm{CH}$, Utton MA, Gibb GM, Yates A, Anderton BH: Stressactivated protein kinase/c-jun N-terminal kinase phosphorylates tau protein. J Neurochem 1997, 68:1736-1744

62. Gong CX, Lidsky T, Wegiel J, Zuck L, Grundke-lqbal I, Iqbal K: Phosphorylation of microtubule-associated protein tau is regulated by protein phosphatase $2 \mathrm{~A}$ in mammalian brain. Implications for neuro- 
fibrillary degeneration in Alzheimer's disease. J Biol Chem 2000, 275:5535-5544

63. Kimura T, Ono T, Takamatsu J, Yamamoto H, Ikegami K, Kondo A, Hasegawa M, Ihara Y, Miyamoto E, Miyakawa T: Sequential changes of tau-site-specific phosphorylation during development of paired helical filaments. Dementia 1996, 7:177-181

64. Schatteman GC, Gibbs L, Lanahan AA, Claude P, Bothwell M: Expression of NGF receptor in the developing and adult primate central nervous system. J Neurosci 1988, 8:860-873

65. Kordower JH, Bartus RT, Bothwell M, Schatteman G, Gash DM: Nerve growth factor receptor immunoreactivity in the nonhuman primate (Cebus apella): distribution, morphology, and colocalization with cholinergic enzymes. J Comp Neurol 1988, 277:465-486

66. Mesulam MM, Mufson EJ, Wainer BH, Levey Al: Central cholinergic pathways in the rat: an overview based on an alternative nomenclature (Ch1-Ch6). Neuroscience 1983, 10:1185-1201

67. Gundersen HJ, Bagger P, Bendtsen TF, Evans SM, Korbo L, Marcussen N, Moller A, Nielsen K, Nyengaard JR, Pakkenberg B: The new stereological tools: disector, fractionator, nucleator and point sampled intercepts and their use in pathological research and diagnosis. APMIS 1988, 96:857-881

68. Pakkenberg B, Moller A, Gundersen HJ, Mouritzen Dam A, Pakkenberg $\mathrm{H}$ : The absolute number of nerve cells in substantia nigra in normal subjects and in patients with Parkinson's disease estimated with an unbiased stereological method. J Neurol Neurosurg Psychiatry 1991, 54:30-33

69. Kanaan NM, Kordower JH, Collier TJ: Age-related accumulation of Marinesco bodies and lipofuscin in rhesus monkey midbrain dopamine neurons: relevance to selective neuronal vulnerability. J Comp Neurol 2007, 502:683-700

70. West MJ: New stereological methods for counting neurons. Neurobiol Aging 1993, 14:275-285

71. West MJ: Stereological methods for estimating the total number of neurons and synapses: issues of precision and bias. Trends Neurosci 1999, 22:51-61
72. Gundersen HJ, Jensen EB, Kieu K, Nielsen J: The efficiency of systematic sampling in stereology-reconsidered. J Microsc 1999, 193:199-211

73. West MJ, Gundersen HJ: Unbiased stereological estimation of the number of neurons in the human hippocampus. J Comp Neurol 1990, 296:1-22

74. Mouton PR, Gokhale AM, Ward NL, West MJ: Stereological length estimation using spherical probes. J Microsc 2002, 206:54-64

75. Price JL, McKeel DW, Jr., Buckles VD, Roe CM, Xiong C, Grundman M, Hansen LA, Petersen RC, Parisi JE, Dickson DW, Smith CD, Davis DG, Schmitt FA, Markesbery WR, Kaye J, Kurlan R, Hulette C, Kurland BF, Higdon R, Kukull W, Morris JC: Neuropathology of nondemented aging: presumptive evidence for preclinical Alzheimer disease. Neurobiol Aging 2009, 30:1026-1036

76. Markesbery WR: Neuropathologic alterations in mild cognitive impairment: a review. J Alzheimers Dis 2010, 19:221-228

77. Mufson EJ, Counts SE, Perez SE, Ginsberg SD: Cholinergic system during the progression of Alzheimer's disease: therapeutic implications. Expert Rev Neurother 2008, 8:1703-1718

78. Geula C, Nagykery N, Wu CK, Bu J: Loss of calbindin-D28K from aging human cholinergic basal forebrain: relation to plaques and tangles. J Neuropathol Exp Neurol 2003, 62:605-616

79. DeKosky ST, Ikonomovic MD, Styren SD, Beckett L, Wisniewski S, Bennett DA, Cochran EJ, Kordower JH, Mufson EJ: Upregulation of choline acetyltransferase activity in hippocampus and frontal cortex of elderly subjects with mild cognitive impairment. Ann Neurol 2002, $51: 145-155$

80. Petersen RC, Smith GE, Waring SC, Ivnik RJ, Tangalos EG, Kokmen E: Mild cognitive impairment: clinical characterization and outcome. Arch Neurol 1999, 56:303-308

81. Luis CA, Loewenstein DA, Acevedo A, Barker WW, Duara R: Mild cognitive impairment: directions for future research. Neurology 2003, 61:438-444

82. Morris JC, Price AL: Pathologic correlates of nondemented aging, mild cognitive impairment, and early-stage Alzheimer's disease. J Mol Neurosci 2001, 17:101-118 